\title{
A Study on Supply Chain Emission Reduction Level Based on Carbon Tax and Consumers' Low-Carbon Preferences under Stochastic Demand
}

\author{
Liang Wang $(\mathbb{D}$, Tingjia Xu $\mathbb{D}$, and Longhao Qin $(\mathbb{1})$ \\ School of Economics and Business Administration, Xian University of Technology, Xian 710048, China \\ Correspondence should be addressed to Liang Wang; wangliang@xaut.edu.cn
}

Received 25 December 2018; Revised 4 April 2019; Accepted 16 April 2019; Published 20 May 2019

Academic Editor: Sitek Paweł

Copyright (C) 2019 Liang Wang et al. This is an open access article distributed under the Creative Commons Attribution License, which permits unrestricted use, distribution, and reproduction in any medium, provided the original work is properly cited.

\begin{abstract}
This article focuses on the level of supply chain emission reduction, taking into account consumers' low-carbon preferences, stochastic market demand, and carbon tax policy. By introducing the emission reduction penalty mechanism and adopting reverse derivation method, it derives the revenue model of the retailer and the manufacturer in decentralized and centralized supply chain when the supply chain reduces emissions or is not under stochastic market demand. The research results are as follows. (i) The optimal retailer's revenue is strictly monotonous increasing with respect to the consumers' low-carbon preferences in the decentralized supply chain. However, in the centralized supply chain, the optimal revenue of the retailer and the manufacturer are strictly monotonously decreasing of the consumers' low-carbon preferences respectively. (ii) The retailer's revenue is a concave function of the order quantity, and there exists a unique order quantity that can maximize retailer's revenue. The manufacturer's revenue is a concave function of the wholesale price, and there exists a unique wholesale price that can maximize manufacturer's revenue. (iii) When consumers' low-carbon preferences are given, there is an optimal emission reduction level that maximizes the overall revenue of the supply chain. Furthermore, as the carbon tax increases, the optimal emission reduction level gradually rises. (iv) As the level of emission reduction in the supply chain increases, the range of the revenue sharing coefficient becomes larger, and it is easier for supply chain members to reach a revenue sharing contract. However, when consumers' low-carbon preferences and carbon tax increase, the opposite is true.
\end{abstract}

\section{Introduction}

In recent years, the trend of global warming has further intensified and has gradually become one of the hot spots of international concern. The development of a low-carbon economy has become one of the major strategic initiatives to promote the sustainable development of the global economy. Many countries have successively introduced a series of policies such as carbon tax, cap-and-trade, and low carbon subsidy policy. In such a global green revolution, consumers are increasingly aware of low-carbon consumption. In order to cope with the pressure from the government and the market, manufacturing companies have proposed carbon emission reduction strategies in the supply chain: first, to increase the transformation and upgrading of the company's carbon emission reduction technology; second, to put forward emission reduction requirements for upstream and downstream suppliers. However, the high level of carbon emission reduction target will undoubtedly increase the operating cost of the entire supply chain, thereby reducing the operational performance of the supply chain. Therefore, it is necessary to study the emission reduction level of supply chain.

The carbon tax policy has been continuously valued by countries all over the world for its simplicity and operability. Carbon tax can limit the total amount of corporate emissions to a given range, which will facilitate companies to change their supply chain management modes, thereby reducing carbon emissions across the supply chain [1]. However, as a means of taxation, carbon tax will inevitably bring additional costs to manufacturing companies, which will have a negative impact on the supply chain operation process $[2,3]$ and also restrict the emission reduction level of companies. 
With the deepening of the global green revolution, consumers' low-carbon preferences are increasing. In order to gain more market share, manufacturing companies will continue to meet market demand through technological innovation of emission reduction. However, technological innovation driven by excessive emission reduction level will increase the production cost of unit product, thus reducing the market competitiveness of products. At the same time, due to uncertainties such as emission reduction technology update, replacement product introduction, and changes in consumer demand, the market demand for products under corporate emission reduction conditions shows higher randomness, and the operational risk of emission reduction companies will be further aggravated when the cost per unit product increases. However, there are certain interaction effects between carbon tax, consumer's low-carbon preferences, and carbon emission reduction: on the one hand, carbon tax will increase the operating cost of companies, while consumers' low-carbon preferences will increase the market demand of low-carbon products and further affect the retail price; on the other hand, to some extent, carbon emission reduction will reduce the cost of carbon tax in supply chain and increase consumers' preference for products, but it will generate emission reduction costs $[4,5]$. In summary, this paper argues that the following issues need to be determined.

(1) Under stochastic market demand, how do we set the emission reduction level of the supply chain when considering the interaction effect of carbon tax and consumers' lowcarbon preferences?

(2) What effect does carbon tax and consumers' preferences have on revenue sharing contracts between supply chain members?

In view of this, this paper first constructs a price function of retail price on consumers' low-carbon preferences and emission reduction level. Based on the penalty mechanism and reverse derivation method, it determines the revenue models of the retailer and the manufacturer when the supply chain reduces emissions or not under stochastic demand and conducts a comparative study from the perspective of decentralized and centralized decision-making. Furthermore, the optimal emission reduction level of supply chain based on carbon tax and consumers' low-carbon preference under stochastic demand is determined by mathematical modeling, and the relationship between parameters is simulated and analyzed by MATLAB. The rest of the paper is organized as follows. Section 2 proposes research questions on the basis of literature review. Section 3 derives the supply chain members' revenue models for decentralized and centralized supply chain under the condition of supply chain emission reduction and nonemission reduction. In Section 4, we determine the optimal emission reduction level based on carbon tax and consumers' low-carbon preferences under stochastic demand through mathematical modeling. In Section 5, we explore the dynamic relationship among decision parameters through simulation analysis. Furthermore, we conclude our research findings in Section 6 with closing remarks.

\section{Literature Review}

The literature reviewed here mainly involves three research directions: (i) carbon tax policy and carbon emission reduction; (ii) supply chain emission reduction decision-making, operational mechanism and cooperation; (iii) consumers' low carbon preferences and supply chain emission reduction.

Carbon tax, as a kind of emission reduction measures with extremely high market efficiency, has been widely used in developed countries and regions. Marron and Toder [6] believed that an effective carbon tax policy can reduce the risk of climate change, minimize the cost of emission reduction, promote the innovation of low-carbon technology, and increase the public revenue of society. Metcalf [7] emphasized that a key factor in using carbon taxes to reduce emissions is the reasonable pricing of greenhouse gas emissions. Chen and Hao [8] found that when a company incurs a higher carbon tax, it will receive a higher percentage of carbon emission reduction, and the carbon tax policy has a greater impact on the carbon reduction of low-efficiency company. Xiang and Lawley [9] found that the carbon tax in British Columbia (BC) significantly reduced the natural gas consumption of local residents by approximately 7\%. Ding, Zhang and Song [10] argued that the increase in carbon taxes could accelerate the spread of energy technologies and significantly reduce carbon discharges peak value. For the economic effect of the carbon tax, Gros et al. [2] thought that the carbon tax will increase the cost of transformation for energy-intensive industries, which in turn will reduce GDP. Liu and Lu [11] believed that the government could reduce the carbon tax collection cost in a disguised manner by reducing production tax and consumption tax, which would be beneficial to the adjustment of the economic structure and the improvement of continuous emission reduction. Xie et al. [3] found that the implementation of carbon tax had a slight negative impact on the economic growth of Chongqing in China. Due to the different geographical location, industrial structure, energy structure, and other characteristics, the impacts of carbon tax on the level of economic activity in different regions are different. Zhao et al. [12] found that when the carbon tax reaches 30 yuan/ton or the free quota of carbon dioxide is less than $50 \%$, Chinese investors prefer wind power generation to coal-fired power generation.

Supply chain emission reduction has become a hot issue in the theoretical and practical fields. In terms of the carbon emission reduction decision-making, Du et al. [13] found that market risk affects carbon emission reduction, while Tao et al. [14] argued that different supply chain forms, such as closed-loop supply chains, also have an impact on carbon emission reduction. Luo et al. [15] found that, under the cap-and-trade policy, coopetition will bring more profits and less total carbon emissions to the two manufacturers. Rao et al. [16] suggested that changes in carbon tax will have an impact on the optimal choice of emission reductions, and, with the increase of carbon tax, carbon emission reductions will present a nonlinear emission reduction trend. Cao et al. [17] studied the impacts of cap-and-trade policy (CTP) and low carbon subsidy policy (LCSP) on manufacturer's production and carbon emission reduction level and believed 
that the carbon emission reduction level increases with the increase in carbon trading price and has nothing to do with the unit low carbon subsidy. Madani and Rasti-Barzoki [18] established a game model for the government providing emission reduction subsidies and carbon tax and analyzed the impact of government fiscal and taxation policies on the optimal emission reduction decisions in the supply chain. For the carbon reduction mechanisms, Drake et al. [19] argue that when a company has a mix of clean and nonclean technologies, investment and subsidies increase the expected emissions to some extent, but do not affect a company's optimal capacity. Fahimnia et al. [20] proposed the way to price carbon for maximum environmental revenue per dollar increase in supply chain cost, which makes it easy for the company to make trade-offs from emission costs. Chen et al. [21] studied the optimal pricing and unit carbon emissions decisions of two manufacturers under the balanced and imbalanced power structures. It was found that, under the balanced power structure, the higher the efficiency of carbon emission reduction, the greater the manufacturer's output and the more investment in green technology. For supply chain cooperation in carbon reduction, Benjaafar et al. [22] argued that it is possible to effectively reduce carbon emissions through operational adjustments and collaboration with supply chain members without significantly increasing costs. Ghosh and Shah [23] found that when supply chain members use cost-sharing contracts for cooperation, the emission reduction level and benefits will be affected by the cost of abatement and consumers' low-carbon preferences. $\mathrm{Yu}$ and Han [24] adopted two types of contracts, i.e., the modified wholesale price (MW) and the modified costsharing contract (MS), and achieved supply chain coordination, which will promote the supply chain efficiency, but will not bring additional benefits to the manufacturer.

To a certain extent, consumers' low-carbon preferences will promote companies to reduce emissions and improve emission reduction technologies. For the role of consumers' low-carbon preferences in reducing emissions, Wang, Zhao \& $\mathrm{He}$ [5] argued that higher consumer's low-carbon preferences will improve the retailer's position in the supply chain revenue sharing contract negotiations, which in turn will enhance the overall emission reduction level of the supply chain. Shewmake et al. [25] found that if consumers are more sensitive to goods with carbon labels, then the value of their individual carbon footprint will be higher, and the simulation results showed that consumers' low-carbon preferences have a more significant effect on carbon emission reduction of alcohol and meat. Xia et al. [26] found that the improvement of consumers' low-carbon awareness encourages supply chain members to invest in emission reduction, which is beneficial to their profits and utilities. For the impact of low-carbon preferences on corporate earnings, Liuabc [27] thought that the increase of consumers' low-carbon preferences will have an impact on the competitive results of supply chain members, but if the cost of abatement does not have an advantage, the profitability of eco-friendly companies will tend to decline. Shuai et al. [28] considered that the education level and monthly income of consumers are the main factors for their purchase of low-carbon products, so consumer choice is the key to determining the benefits of low-carbon products of the manufacturer. Du et al. [13] constructed an emission-sensitive demand function considering consumers' low-carbon preferences and analyzed the impact of lowcarbon preferences on market demand and supply chain members' returns.

For the issue of supply chain emission reduction, the previous literatures did not consider the effects of market stochastic demand, carbon tax, and consumers' low-carbon preferences simultaneously. Moreover, when constructing the revenue model of supply chain, the retail price is usually regarded as a constant, ignoring the dynamic effects of carbon emissions and other factors on the retail price, which is inconsistent with the reality $[13,18,22]$. In view of this, the main innovations of this paper are as follows. Firstly, it constructs a function of retail price on consumers' lowcarbon preferences and emission reduction level. Secondly, introducing the emission reduction penalty mechanism and adopting the reverse derivation method, it derives revenue models of the retailer and the manufacturer in decentralized and centralized supply chain when the supply chain reduces emissions or not under stochastic market demand. Thirdly, it investigates the optimal emission reduction level by mathematical modeling.

\section{Basic Assumptions and Model Building}

This paper considers a two-stage supply chain system consisting of one manufacturer $P$ and one retailer $S$. The information between members is completely symmetrical. In the process of revenue decision-making, the manufacturer as the leader first selects the wholesale price, and the retailer acts as the follower and then determines the order quantity.

\subsection{Basic Assumptions}

Assumption 1. In order to strengthen the emission reduction, it is assumed that the government will impose penalties on the manufacturer that does not reduce emissions. The fine is $\eta(\eta<0.5)$ times the wholesale price of the unit product, and the government imposes a carbon tax of $\$ t$ on the carbon emissions per unit.

Assumption 2. It is assumed that the carbon emission of the manufacturer's unit product is $e_{0}$, which also represents the production technology level of the manufacturer. The smaller the $e_{0}$, the higher the production technology level of the manufacturer. Consumers have low-carbon preferences, and we assume that the purchase price $p$ that they are willing to pay depends on the manufacturer's carbon emissions, where $p=v-k\left(e_{0} \times h-\Delta e\right) . v$ is a constant, $k$ denotes the consumer's sensitivity to the carbon footprint, and the carbon reduction level of the supply chain $\Delta e$ is a continuous variable.

Assumption 3. It is assumed that the manufacturer's emission reduction cost is $\gamma \Delta e^{2}, \gamma$ is the cost coefficient, and $h$ is the retailer's order quantity; when the manufacturer does not reduce emissions, $\Delta e=0$. In the centralized supply chain, the manufacturer shares revenue with the retailer through the 
TABLE 1: Parameters and variables.

\begin{tabular}{lr}
\hline Notation & Descriptions \\
\hline$\eta$ & Fine multiple of the wholesale price of the unit product., $0<\eta<0.5$ \\
$t$ & Tax per unit of carbon emissions. \\
$e_{0}$ & The carbon emissions of the manufacturer's unit product, it also represents the manufacturer's production technology level. \\
$p$ & The purchase price that consumers are willing to pay, $p=v-k\left(e_{0} \times h-\Delta e\right)$. \\
$v$ & Constant. \\
$k$ & Consumer's sensitivity to the carbon footprint. \\
$\Delta e$ & Carbon emission reduction level of the supply chain. \\
$\gamma \Delta e^{2}$ & Manufacturer's emission reduction cost. \\
$\gamma$ & Emission reduction cost coefficient \\
$h$ & Retailer's order quantity \\
$\varphi$ & Revenue sharing coefficient, that is, the ratio of the sales revenue of the retailer. \\
$1-\varphi$ & The ratio of the sales revenue of the manufacturer. \\
$x$ & Consumer demand \\
$c$ & Direct production cost of the manufacturer's yielding unit goods. \\
$s_{1}$ & Publicity expense of the unit product. \\
$s_{2}$ & Storage and transportation cost of the unit product.
\end{tabular}

revenue sharing contract, and the revenue sharing coefficient is $\varphi$. That is, the ratio of the sales revenue of the retailer is $\varphi$, and the remaining $1-\varphi$ is transferred to the manufacturer.

Assumption 4. It is assumed that the consumer demand $x$ is stochastic, the density function and distribution function of $x$ remain unchanged before and after the manufacturer adopts low-carbon technology, and the distribution function is the increasing failure rate (IFR) function.

Assumption 5. It is assumed that the direct production cost is $c$ for the manufacturer's yielding unit goods, $s_{1}$ is the publicity expense of the unit product, and $s_{2}$ is the storage and transportation cost of the unit product (the above parameters are all greater than zero).

In order to intuitively demonstrate the meaning of each parameter and variable in the above assumptions, we present the symbols and definitions of the parameters in Table 1.

3.2. Model Construction. This paper first divides the supply chain into two types according to whether or not reducing emissions. Next, it further discusses the revenue model, wholesale price, order quantity of the supply chain from decentralized, and centralized decision-making.

3.2.1. Revenue Model with Non-Emission Reduction under Stochastic Demand in the Supply Chain. When the supply chain does not reduce emissions, the level of carbon emission reduction is $\Delta e=0$, then the retail price of the product is $p=$ $v-k e_{0} h$, and the expectation of consumers with stochastic demand is $\int_{0}^{h} x f(x) d x+\int_{h}^{+\infty} h f(x) d x$. The manufacturer first gives the wholesale price $u$, and the retailer determines the order quantity $h$ based on the wholesale price, market demand and retail price. Let $y_{S}(h, \varphi)$ and $y_{P}(u, \varphi)$ denote the expected revenue of the retailer and the manufacturer when they do not reduce emissions, respectively, and we have

$$
\begin{aligned}
& y_{S}(h, \varphi)=\varphi p\left[\int_{0}^{h} x f(x) d x+\int_{h}^{+\infty} h f(x) d x\right] \\
& -\left(u+s_{1}+s_{2}\right) h=\varphi\left(v-k e_{0} h\right) \\
& \cdot\left[\int_{0}^{h} x f(x) d x+\int_{h}^{+\infty} h f(x) d x\right]-\left(u+s_{1}+s_{2}\right) h \\
& y_{P}(u, \varphi)=\left[u(1-\eta)-c-e_{0} t\right] h+(1-\varphi) \\
& \cdot p\left[\int_{0}^{h} x f(x) d x+\int_{h}^{+\infty} h f(x) d x\right] \\
& =\left[u(1-\eta)-c-e_{0} t\right] h+(1-\varphi)\left(v-k e_{0} h\right) \\
& \cdot\left[\int_{0}^{h} x f(x) d x+\int_{h}^{+\infty} h f(x) d x\right]
\end{aligned}
$$

Proposition 6. When the supply chain does not reduce emissions, the retailer's revenue is a concave function of the order quantity, and there is a unique order quantity that maximizes the retailer's revenue.

Proof. The first-order partial derivative of (1) on order quantity $h$ is

$$
\begin{aligned}
& \frac{\partial y_{S}(h, \varphi)}{\partial h} \\
& \quad=\left\{\left(-k e_{0}\right)\left[\int_{0}^{h} x f(x) d x+\int_{h}^{+\infty} h f(x) d x\right]\right. \\
& \left.\quad+\left(v-k e_{0} h\right)[1-F(h)]\right\}-\left(u+s_{1}+s_{2}\right)
\end{aligned}
$$


And the second-order partial derivative of Eq. (1) on $h$ is

$$
\begin{aligned}
& \frac{\partial^{2} y_{S}(h, \varphi)}{\partial h^{2}} \\
& \quad=\varphi\left\{\left(-2 k e_{0}\right)[1-F(h)]-\left(v-k e_{0} h\right) f(h)\right\}
\end{aligned}
$$

Because the retail price $p=v-k e_{0} h>0$, the consumers' sensitivity to the carbon footprint $k>0$, the level of carbon emissions $e_{0}>0$, and the revenue sharing coefficient $\varphi>0$; hence, there is $\partial^{2} y_{S}(h, \varphi) / \partial h^{2}<0$. Therefore, the retailer's revenue $y_{S}(h, \varphi)$ is a concave function of the order quantity $h$, and there is a unique order quantity that maximizes the retailer's revenue.

When (3) equals zero, the order quantity $h$ and the wholesale price $u$ satisfies the relationship of

$$
\begin{aligned}
& \varphi\left\{\left(-k e_{0}\right)\left[\int_{0}^{h} x f(x) d x+\int_{h}^{+\infty} h f(x) d x\right]\right. \\
& \left.+\left(v-k e_{0} h\right)[1-F(h)]\right\}-\left(u+s_{1}+s_{2}\right)=0
\end{aligned}
$$

(1) Revenue of the Retailer and the Manufacturer in the Decentralized Supply Chain. Let $u^{D}, h^{D}$, respectively, indicate the manufacturer's wholesale price and the retailer's order quantity in the decentralized supply chain and $y_{P}^{D}, y_{S}^{D}$ denote the revenue of the retailer and manufacturer in the decentralized supply chain with no reducing emissions, and the revenue sharing coefficient $\varphi=1$. In order to maximize his own profits, the retailer will make $u^{D}$ and $h^{D}$ satisfy the functional relationship in (5), and the wholesale price will be further obtained:

$$
\begin{aligned}
u^{D}= & {\left[1-F\left(h^{D}\right)\right]\left(v-2 k e_{0} h^{D}\right)-k e_{0} \int_{0}^{h^{D}} x f(x) d x } \\
& -s_{1}-s_{2}
\end{aligned}
$$

Proposition 7. In the decentralized supply chain with no reducing emissions, the manufacturer's revenue is a concave function of the wholesale price, and there is a unique wholesale price that can maximize the manufacturer's revenue.

Proof. It can be known from (2) that when the revenue sharing coefficient $\varphi=1$, the revenue function of the manufacturer is $y_{P}^{D}\left(u^{D}\right)$. The first-order partial derivative of $y_{P}^{D}\left(u^{D}\right)$ on $u^{D}$ is

$$
\frac{\partial y_{P}^{D}\left(u^{D}\right)}{\partial u^{D}}=h^{D}(1-\eta)+\left[u^{D}(1-\eta)-c_{m}-e_{0} t\right] \frac{\partial h^{D}}{\partial u^{D}}
$$

The second-order partial derivative of $y_{P}^{D}\left(u^{D}\right)$ on $u^{D}$ is

$$
\begin{aligned}
\frac{\partial^{2} y_{P}^{D}\left(u^{D}\right)}{\partial\left(u^{D}\right)^{2}}= & 2 \times \frac{\partial h^{D}}{\partial u^{D}}(1-\eta) \\
& +\left[u^{D}(1-\eta)-c_{m}-e_{0} t\right] \frac{\partial^{2} h^{D}}{\partial\left(u^{D}\right)^{2}}
\end{aligned}
$$

The first-order partial derivative of (5) on $u^{D}$ is

$$
\frac{\partial h^{D}}{\partial u^{D}}=\frac{-1}{\left(2 k e_{0}\right)\left[1-F\left(h^{D}\right)\right]+\left(v-k e_{0} h^{D}\right)\left(f\left(h^{D}\right)\right)}
$$

Further, the second-order partial derivative of $h^{D}$ on $u^{D}$ is

$$
\begin{aligned}
& \frac{\partial^{2} h^{D}}{\partial\left(u^{D}\right)^{2}} \\
& =\frac{-\left(\partial h^{D} / \partial u^{D}\right)^{2}\left[\left(v-k e_{0} h^{D}\right) f^{\prime}\left(h^{D}\right)-3 k e_{0} f\left(h^{D}\right)\right]}{\left(2 k e_{0}\right)\left[1-F\left(h^{D}\right)\right]+\left(v-k e_{0} h^{D}\right) f\left(h^{D}\right)}
\end{aligned}
$$

Substitute (9) and (10) into (8), we can obtain

$$
\frac{\partial^{2} y_{P}^{D}\left(u^{D}\right)}{\partial\left(u^{D}\right)^{2}}=\frac{\partial h^{D}}{\partial u^{D}} \times L
$$

where

$L$

$$
=\frac{2(1-\eta)\left\{2 k e_{0}\left[1-F\left(h^{D}\right)\right]+\left(v-k e_{0} h^{D}\right) f\left(h^{D}\right)\right\}^{2}+\left[u^{D}(1-\eta)-c-e_{0} t\right] \times\left[\left(v-k e_{0} h^{D}\right) f^{\prime}\left(h^{D}\right)-3 k e_{0} f\left(h^{D}\right)\right]}{\left\{2 k e_{0}\left[1-F\left(h^{D}\right)\right]+\left(v-k e_{0} h^{D}\right) f\left(h^{D}\right)\right\}^{2}}
$$

We rewrite the numerator of $L$ and get

$$
\begin{aligned}
& 2(1-\eta)\left\{\left(2 k e_{0}\right)\left[1-F\left(h^{D}\right)\right]+\left(v-k e_{0} h^{D}\right) f\left(h^{D}\right)\right\}^{2}+\left[u^{D}(1-\eta)-c-e_{0} t\right] \times\left[\left(v-k e_{0} h^{D}\right) f^{\prime}\left(h^{D}\right)-3 k e_{0} f\left(h^{D}\right)\right] \\
& \quad=2(1-\eta)\left\{4 k^{2} e_{0}^{2}\left[1-F\left(h^{D}\right)\right]^{2}+\left(4 k e_{0}\right)\left[1-F\left(h^{D}\right)\right]\left(v-k e_{0} h^{D}\right) f\left(h^{D}\right)+\left(v-k e_{0} h^{D}\right)^{2} f^{2}\left(h^{D}\right)\right\}
\end{aligned}
$$




$$
\begin{aligned}
& +\left[u^{D}(1-\eta)-c-e_{0} t\right]\left(v-k e_{0} h^{D}\right) f^{\prime}\left(h^{D}\right)-\left[u^{D}(1-\eta)-c-e_{0} t\right] 3 k e_{0} f\left(h^{D}\right)=2(1-\eta) 4 k^{2} e_{0}^{2}\left[1-F\left(h^{D}\right)\right]^{2} \\
& +2(1-\eta)\left(4 k e_{0}\right)\left[1-F\left(h^{D}\right)\right]\left(v-k e_{0} h^{D}\right) f\left(h^{D}\right)+2(1-\eta)\left(v-k e_{0} h^{D}\right)^{2} f^{2}\left(h^{D}\right) \\
& +\left[u^{D}(1-\eta)-c-e_{0} t\right]\left(v-k e_{0} h^{D}\right) f^{\prime}\left(h^{D}\right)+f^{2}\left(h^{D}\right)\left(v-k e_{0} h^{D}\right)^{2}-f^{2}\left(h^{D}\right)\left(v-k e_{0} h^{D}\right)^{2} \\
& -\left[u^{D}(1-\eta)-c-e_{0} t\right] 3 k e_{0} f\left(h^{D}\right)=\underbrace{2(1-\eta) 4 k^{2} e_{0}^{2}\left[1-F\left(h^{D}\right)\right]^{2}}_{\text {first part }} \\
& +\underbrace{k e_{0} f\left(h^{D}\right)\left\{8(1-\eta)\left[1-F\left(h^{D}\right)\right]\left(v-k e_{0} h^{D}\right)-3\left[u^{D}(1-\eta)-c-e_{0} t\right]\right\}}_{\text {second part }} \\
& +\underbrace{\left[u^{D}(1-\eta)-c-e_{0} t\right]\left(v-k e_{0} h^{D}\right) f^{\prime}\left(h^{D}\right)+f^{2}\left(h^{D}\right)\left(v-k e_{0} h^{D}\right)^{2}}_{\text {third part }}+\underbrace{f^{2}\left(h^{D}\right)\left(v-k e_{0} h^{D}\right)^{2}[2(1-\eta)-1]}_{\text {fourth part }}
\end{aligned}
$$

Based on the previous assumptions, it illustrates the manufacturer's profit $u(1-\eta)-c-e_{0} t>0$. Furthermore, the penalty coefficient $\eta<0.5$; otherwise it will cause a loss for the manufacturer. Since the first part and the fourth part in (13) are both greater than zero, we further analyze the characteristic of the second part and the third part in it.

For the second part in (13), we firstly substitute $v-2 k e_{0} h^{D}$ in (6) with $v-k e_{0} h^{D}$ and obtain

$$
\begin{aligned}
(1 & \left.-F\left(h^{D}\right)\right)\left(v-k e_{0} h^{D}\right) \\
& >\left(u^{D}+s_{1}+s_{2}\right)+k e_{0} \int_{0}^{h^{D}} x f(x) d x \\
& >u^{D}(1-\eta)-c-e_{0} t
\end{aligned}
$$

Hence, it can be deduced that the second part in (13) is greater than zero.

We further analyze the third part of (13). Since consumer demand distribution function $x$ has a characteristic of increasing failure rate (IFR), that is, $(f(x) /(1-F(x)))^{\prime} \geq 0$ and $f^{\prime}(x)[1-F(x)] \geq-f^{2}(x)$, there exist

$$
\begin{aligned}
\frac{f^{\prime}\left(h^{D}\right)}{f^{2}\left(h^{D}\right)} & \geq-\frac{1}{\left[1-F\left(h^{D}\right)\right]} \\
& =-\frac{v-2 k e_{0} h^{D}}{\left(u^{D}+s_{1}+s_{2}\right)+k e_{0} \int_{0}^{h^{D}} x f(x) d x}
\end{aligned}
$$

$$
>-\frac{v-k e_{0} h^{D}}{\left[u^{D}(1-\eta)-c_{m}-e_{0} t\right]}
$$

that is, $f^{\prime}\left(h^{D}\right) / f^{2}\left(h^{D}\right)>-\left(v-k e_{0} h^{D}\right) /\left[u^{D}(1-\eta)-c_{m}-e_{0} t\right]$.

We further have $\left[u^{D}(1-\eta)-c_{m}-e_{0} t\right] f^{\prime}\left(h^{D}\right)+f^{2}\left(h^{D}\right)(v-$ $\left.k e_{0} h^{D}\right)>0$. Hence, it is multiplied both sides by $p=v-$ $k e_{0} h^{D}$, and we deduce that the third part in (13) is greater than zero. For $\partial h^{D} / \partial u^{D}<0$ in (9), it shows $\partial^{2} y_{P}^{D}\left(u^{D}\right) / \partial u^{D^{2}}<0$ in (8). It can be seen that the manufacturer's revenue is a concave function of the wholesale price, and there exists a unique wholesale price at which the manufacturer has the greatest benefit when $\partial h^{D} / \partial u^{D}=0$.

According to (5), $u^{D}$ is expressed as a function of $h^{D}$, and we can obtain the first partial derivative of (2) on $h^{D}$; that is,

$$
\begin{aligned}
& \frac{\partial y_{P}^{D}\left(h^{D}\right)}{\partial h^{D}}=(1-\eta)\left\{\left[1-F\left(h^{D}\right)\right]\left(v-4 k e_{0} h^{D}\right)\right. \\
& -h^{D} f\left(h^{D}\right)\left(v-k e_{0} h^{D}\right)-k e_{0} \int_{0}^{h^{D}} x f(x) d x \\
& \left.-\left(s_{1}+s_{2}\right)\right\}-c-e_{0} t
\end{aligned}
$$

When (16) equals zero, the optimal wholesale price of the manufacturer in the decentralized supply chain is

$$
u^{D^{*}}=\frac{\left\{\left[2 k e_{0}\left[1-F\left(h^{D^{*}}\right)\right]+f\left(h^{D^{*}}\right)\left(v-k e_{0} h^{D^{*}}\right)\right](1-\eta)\right\} h^{D^{*}}+c+e_{0} t}{1-\eta}
$$

After the manufacturer determines the optimal wholesale price, the retailer acts as the follower to match the optimal order quantity. At this time, the optimal expected revenue for the retailer and the manufacturer is 


$$
\begin{aligned}
& y_{S}^{D *}\left(h^{D^{*}}\right)=v \int_{0}^{h^{D^{*}}} x f(x) d x \\
& +h^{D^{*}} k e_{0} \int_{h^{D^{*}}}^{+\infty} h^{D^{*}} f(\xi) d \xi \\
& y_{p}^{D *}\left(u^{D^{*}}\right) \\
& \quad=\left\{\left[2 k e_{0} \int_{h^{D^{*}}}^{+\infty} f(x) d x+f\left(h^{D^{*}}\right)\left(v-k e_{0} h^{D^{*}}\right)\right]\right. \\
& \cdot(1-\eta)\}\left(h^{D^{*}}\right)^{2}
\end{aligned}
$$

(2) Revenue of the Retailer and the Manufacturer in the Centralized Supply Chain. According to (1) and (2), the expected revenue of the supply chain as a whole is

$$
\begin{aligned}
y^{C} & \\
= & \left(v-k e_{0} h^{C}\right)\left[\int_{0}^{h^{C}} x f(x) d x+\int_{h^{C}}^{+\infty} h^{C} f(x) d x\right] \\
& -\left(u^{C}+s_{1}+s_{2}\right) h^{C}+\left[u^{C}(1-\eta)-c-e_{0} t\right] h^{C}
\end{aligned}
$$

The first-order partial derivative of (20) on $h^{C}$ is

$$
\begin{aligned}
\frac{\partial y^{C}}{\partial h^{C}}= & \left(-k e_{0}\right)\left[\int_{0}^{h^{C}} x f(x) d x+\int_{h^{C}}^{+\infty} h^{C} f(x) d x\right] \\
& +\left(v-k e_{0} h^{C}\right)\left[1-F\left(h^{C}\right)\right]-\left(u^{C}+s_{1}+s_{2}\right) \\
& +\left[u^{C}(1-\eta)-c-e_{0} t\right]
\end{aligned}
$$

When (21) equals 0 , the order quantity $h^{C^{\prime}}$ in the centralized supply chain can be obtained, and the total revenue of the supply chain reaches the maximum $y^{C^{\prime}}$. In the centralized supply chain, if the supply chain members reach a revenue sharing contract, the revenue sharing coefficient in (1) and (2) is $\varphi \neq 0$. According to the characteristics of the revenue sharing contract, the retailer's optimal order quantity decision, $h=h^{C^{\prime}}$, needs to make the total revenue of the decentralized supply chain equal to that of the centralized supply chain; that is, $y_{S}(h, \varphi)+y_{P}(u, \varphi)=$ $y^{C^{\prime}}$. From (5) and (21), the following equation set can be obtained:

$$
\begin{aligned}
\varphi & \left\{-k e_{0}\left[\int_{0}^{h} x f(x) d x+\int_{h}^{+\infty} h f(x) d x\right]\right. \\
& \left.+\left(v-k e_{0} h\right)[1-F(h)]\right\}-\left(u+s_{1}+s_{2}\right)=0
\end{aligned}
$$

$$
\begin{aligned}
& -k e_{0}\left(\int_{0}^{h^{C}} x f(x) d x+\int_{h^{\mathrm{C}}}^{+\infty} h^{\mathrm{C}} f(x) d x\right)+(v \\
& \left.-k e_{0} h^{\mathrm{C}}\right)\left[1-F\left(h^{\mathrm{C}}\right)\right]-\left(u+s_{1}+s_{2}\right)+[u(1-\eta) \\
& \left.-c-e_{0} t\right]=0
\end{aligned}
$$

And it can be deduced that the optimal wholesale price in the centralized supply chain without reducing emissions is

$$
u^{C^{*}}=\frac{\left(s_{1}+s_{2}\right)(\varphi-1)+\varphi\left(c+e_{0} t\right)}{1-\varphi \eta}
$$

By substituting (23) into (5), we can obtain the optimal order quantity $y^{C *}$, and it satisfies the following equation:

$$
\begin{aligned}
\left(v-k e_{0} h^{C^{*}}\right)\left[1-F\left(h^{C^{*}}\right)\right] & \\
= & \frac{\left(s_{1}+s_{2}\right)(1-\eta)+c+e_{0} t}{1-\varphi \eta} \\
& +k e_{0}\left[\int_{0}^{h^{C^{*}}} x f(x) d x+\int_{h^{C^{*}}}^{+\infty} h^{C^{*}} f(x) d x\right]
\end{aligned}
$$

For the centralized supply chain without reducing emissions, the optimal expected revenue of the retailer and the manufacturer is

$$
\begin{aligned}
& y_{S}^{C^{*}}\left(h^{C^{*}}, \varphi\right)=\varphi\left[v \int_{0}^{h^{C^{*}}} x f(x) d x\right. \\
& \left.+h^{C^{*}} k e_{0} \int_{h^{C^{*}}}^{+\infty} h^{C^{*}} f(x) d x\right] \\
& y_{P}^{C^{*}}\left(u^{C^{*}}, \varphi\right)=(1-\varphi)\left[v \int_{0}^{h^{C^{*}}} x f(x) d x\right. \\
& \left.+h^{C^{*}} k e_{0} \int_{h^{C^{*}}}^{+\infty} h^{C^{*}} f(x) d x\right]
\end{aligned}
$$

It can be seen from (25) and (26) that the retailer's revenue in the centralized supply chain increases with the rise of the revenue sharing coefficient $\varphi$, while the manufacturer's revenue is getting smaller with it. Since the participants can care for the overall revenue of the supply chain only under the premise of maximizing their own revenue, therefore, the benefits of the retailer and the manufacturer in centralized supply chain cannot be less than the benefits of decentralized supply chain. As far as this premise is met, the retailer and the manufacturer will reach a revenue sharing contract.

Hence, there exist $y_{S}^{C^{*}}\left(h^{C^{*}}, \varphi\right) \geq y_{S}^{D *}\left(h^{D^{*}}\right), y_{P}^{C^{*}}\left(u^{C^{*}}, \varphi\right) \geq$ $y_{p}^{D *}\left(u^{D^{*}}\right)$, and we can further obtain an inequality about the revenue sharing coefficient $\varphi$ : 


$$
\begin{gathered}
1-\frac{\left\{\left[2 k e_{0} \int_{h^{D^{*}}}^{+\infty} f(x) d x+f\left(h^{D^{*}}\right)\left(v-k e_{0} h^{D^{*}}\right)\right](1-\eta)\right\}\left(h^{D^{*}}\right)^{2}}{v \int_{0}^{h^{C^{*}}} x f(x) d x+h^{C^{*}} k e_{0} \int_{h^{C^{*}}}^{+\infty} h^{C^{*}} f(x) d x} \geq \varphi \\
\geq \frac{v \int_{0}^{h^{D^{*}}} x f(x) d \xi+h^{D^{*}} k e_{0} \int_{h^{D^{*}}}^{+\infty} h^{D^{*}} f(x) d x}{v \int_{0}^{h^{C^{*}}} x f(x) d x+h^{C^{*}} k e_{0} \int_{h^{C *}}^{+\infty} h^{C^{*}} f(x) d x}
\end{gathered}
$$

When the revenue sharing contract is reached, the retailer and the manufacturer can get more profits only if the value of $\varphi$ satisfies (27), and the value of $\varphi$ is determined not only by the position of the retailer and the manufacturer in the supply chain but also by their own negotiating abilities.

3.2.2. Revenue Model with Emission Reduction under Stochastic Demand in the Supply Chain. When the manufacturer reduces emissions, the expected consumers' stochastic demand is expressed as $\int_{0}^{h} x f(x) d x+\int_{h}^{+\infty} h f(x) d x$. Let $y_{S}^{R}\left(h^{R}, \varphi\right)$ and $y_{P}^{R}\left(u^{R}, \varphi\right)$ denote the expected revenue of the retailer and the manufacturer with emission reduction, respectively. From (1) and (2), we can get

$$
\begin{aligned}
y_{S}^{R}\left(h^{R}, \varphi\right)= & \varphi\left[v-k\left(e_{0} \times h^{R}-\Delta e\right)\right] \\
& \times\left[\int_{0}^{h^{R}} x f(x) d x+\int_{h^{R}}^{+\infty} h^{R} f(x) d x\right] \\
& -\left(u^{R}+s_{1}+s_{2}\right) h^{R} \\
y_{P}^{R}\left(u^{R}, \varphi\right)= & \left(u^{R}-c\right) h^{R}-\left(e_{0} h^{R}-\Delta e\right) t \\
& +(1-\varphi)\left[v-k\left(e_{0} \times h^{R}-\Delta e\right)\right] \\
& \times\left[\int_{0}^{h^{R}} x f(x) d x+\int_{h^{R}}^{+\infty} h^{R} f(x) d x\right] \\
& -\gamma \Delta e^{2}
\end{aligned}
$$

Let the first-order partial derivative of (28) on $h^{R}$ equal 0 ; hence, the retailer's optimal order quantity can satisfy the following equation:

$$
\begin{aligned}
& \varphi\left\{\left(-k e_{0}\right) \int_{0}^{h^{R}} x f(x) d x\right. \\
& \left.\quad+\left[v-k\left(2 e_{0} h^{R}-\Delta e\right)\right] \int_{h^{R}}^{+\infty} f(x) d x\right\}=u^{R}+s_{1} \\
& \quad+s_{2}
\end{aligned}
$$

Proposition 8. When the supply chain reduces emission, the retailer's revenue is a concave function of the order quantity, and there exists a unique order quantity that can maximize the retailer's revenue; the manufacturer's revenue function is a concave function of the wholesale price, and there exists a unique wholesale price that can maximize the manufacturer's revenue.

The proof process of Proposition 8 is the same as Propositions 6 and 7. Moreover, we will analyze the revenue of the retailer and the manufacturer in the decentralized and centralized supply chain with emission reduction.

(1) Revenue of the Retailer and the Manufacturer in the Decentralized Supply Chain. In the decentralized supply chain, the revenue sharing coefficient $\varphi=1$ and the order quantity $h^{R D}$ satisfying (30) are the optimal order quantity of the retailer. According to (30), it can be seen that the retailer's optimal order quantity is a function of the manufacturer's wholesale price $u^{R D}$. By substituting $h^{R D}$ into (29) and replacing $u^{R D}$, we further obtain the first-order partial derivative on $h^{R D}$ :

$$
\begin{aligned}
& \frac{\partial y_{P}^{R D}\left(u^{R D}, \varphi\right)}{\partial h^{R D}}=\left\{\left(-k e_{0}\right) h^{R D} f\left(h^{R D}\right)\right. \\
& -2 k e_{0} \int_{h^{R D}}^{+\infty} f(x) d x+\left[v-k\left(2 e_{0} h^{R D}-\Delta e\right)\right] \\
& \left.\quad \times\left[-f\left(h^{R D}\right)\right]\right\} h^{R D}+\left\{\left(-k e_{0}\right) \int_{0}^{h^{R D}} x f(x) d x\right. \\
& +\left[v-k\left(2 e_{0} h^{R D}-\Delta e\right)\right] \int_{h^{R D}}^{+\infty} f(x) d x-\left(s_{1}+s_{2}\right) \\
& -c\}-e_{0} t
\end{aligned}
$$

Let the above equation be zero, and we get the manufacturer's optimal wholesale price

$$
\begin{aligned}
& u^{R D *}=\left\{2 k e_{0} \int_{h^{R D *}}^{+\infty} f(x) d x\right. \\
& \left.+\left[v-k\left(e_{0} h^{R D *}-\Delta e\right)\right] f\left(h^{R D *}\right)\right\} h^{R D *}+e_{0} t+c
\end{aligned}
$$

where $h^{R D *}$ is the optimal order quantity corresponding to $u^{R D *}$. For decentralized supply chain with emission reductions, the optimal expected revenue for the retailer and the manufacturer is

$$
\begin{aligned}
& y_{S}^{R D *}\left(h^{R D *}\right)=(v+k \Delta e) \int_{0}^{h^{R D *}} x f(x) d x \\
& +k e_{0} h^{R D *} \int_{h^{R D *}}^{+\infty} h^{R D *} f(x) d x
\end{aligned}
$$




$$
\begin{aligned}
& y_{P}^{R D *}\left(u^{R D *}\right)=\left\{2 k e_{0} \int_{h^{R D *}}^{+\infty} f(x) d x\right. \\
& \left.+\left[v-k\left(e_{0} h^{R D *}-\Delta e\right)\right] f\left(h^{R D *}\right)\right\}\left(h^{R D *}\right)^{2}+\Delta e t \\
& \quad-\gamma \Delta e^{2}
\end{aligned}
$$

(2) Revenue of the Retailer and the Manufacturer in the Centralized Supply Chain. In the centralized supply chain, the revenue sharing coefficient $\varphi \neq 1$, and the expected revenue of the overall supply chain under emission reduction is

$$
\begin{aligned}
y^{R C}= & {\left[v-k\left(e_{0} \times h^{R C}-\Delta e\right)\right] } \\
& \cdot\left[\int_{0}^{h^{R C}} x f(x) d x+\int_{h^{R C}}^{+\infty} h^{R C} f(x) d x\right] \\
& -\left(s_{1}+s_{2}+c\right) h^{R C}-\left(e_{0} \times h^{R C}-\Delta e\right) t-\gamma \Delta e^{2}
\end{aligned}
$$

The first-order partial derivative of (35) on $h^{R C}$ is

$$
\begin{aligned}
\frac{\partial y^{R C}}{\partial h^{R C}}= & -k e_{0}\left[\int_{0}^{h^{R C}} x f(x) d x+\int_{h^{R C}}^{+\infty} h^{R C} f(x) d x\right] \\
& +\left[v-k\left(e_{0} \times h^{R C}-\Delta e\right)\right] \\
& \times\left[\int_{h^{R C}}^{+\infty} f(x) d x\right]-\left(s_{1}+s_{2}+c\right)-e_{0} t
\end{aligned}
$$

When (36) equals 0 , the optimal order quantity $h^{R C^{\prime}}$ of the supply chain can be obtained, and the overall benefit of the supply chain reaches the maximum. According to the characteristics of the revenue sharing contract, the retailer's optimal order quantity decision, $h^{R}=h^{R C^{\prime}}$, needs to make the total revenue in the decentralized supply chain equal to that of the centralized supply chain. Referring to (30) and (36), the following equation set is obtained:

$$
\begin{aligned}
& \varphi\left\{\left(-k e_{0}\right) \int_{0}^{h^{R}} x f(x) d x\right. \\
& \left.\quad+\left[v-k\left(2 e_{0} h^{R}-\Delta e\right)\right] \int_{h^{R}}^{+\infty} f(x) d x\right\}-\left(u^{R}+s_{1}\right. \\
& \left.\quad+s_{2}\right)=0
\end{aligned}
$$

$$
\begin{aligned}
& -k e_{0}\left[\int_{0}^{h^{R C}} x f(x) d x+\int_{h^{R}}^{+\infty} h^{R C} f(x) d x\right]+[v \\
& \left.-k\left(e_{0} \times h^{R C}-\Delta e\right)\right]\left[\int_{h^{R C}}^{+\infty} f(x) d x\right]-\left(s_{1}+s_{2}\right. \\
& +c)-e_{0} t=0
\end{aligned}
$$

By solving the above equation set, the optimal wholesale price for centralized supply chain with emission reduction can be obtained; that is,

$$
u^{R C *}=\left(s_{1}+s_{2}\right)(\varphi-1)+\varphi\left(c+e_{0} t\right)
$$

Substituting (38) into (30), the optimal order quantity $h^{R C *}$ corresponding to $u^{R C *}$ satisfies the following equation:

$$
\begin{aligned}
&\left(-k e_{0}\right) {\left[\int_{0}^{h^{R C *}} x f(x) d x+\int_{h^{R C *}}^{+\infty} h^{R C *} f(x) d x\right] } \\
&+ {\left[v-k\left(e_{0} \times h^{R C *}-\Delta e\right)\right] \int_{h^{R C *}}^{+\infty} f(x) d x } \\
&-\left(c+e_{0} t+s_{1}+s_{2}\right)=0
\end{aligned}
$$

For the centralized supply chain with emission reduction, the optimal expected revenue of the retailer and the manufacturer are as follows:

$$
\begin{aligned}
& y_{S}^{R C *}\left(h^{R C *}, \varphi\right)=\varphi\left[(v+k \Delta e) \int_{0}^{h^{R C *}} x f(x) d x\right. \\
& \left.\quad+k e_{0} h^{R C *} \int_{h^{R C *}}^{+\infty} h^{R C *} f(x) d x\right] \\
& y_{P}^{R C *}\left(u^{R C *}, \varphi\right)=(1-\varphi)\left[(v+k \Delta e) \int_{0}^{h^{R C *}} x f(x) d x\right. \\
& \left.+k e_{0} h^{R C *} \int_{h^{R C *}}^{+\infty} h^{R C *} f(x) d x\right]+\Delta e t-\gamma \Delta e^{2}
\end{aligned}
$$

Using the same analysis method as Section 3.2.1 (2), this section considers that the benefits of the retailer and the manufacturer in the centralized supply chain cannot be less than the benefits obtained in the decentralized supply chain; hence, we have $y_{S}^{R C *}\left(h^{R C *}\right) \geq y_{S}^{R D *}\left(h^{R D *}\right)$ and $y_{P}^{R C *}\left(u^{R C *}\right) \geq$ $y_{P}^{R D *}\left(u^{R D *}\right)$. Furthermore, we get an inequality about the revenue sharing coefficient $\varphi$ :

$$
\begin{gathered}
1-\frac{\left\{2 k e_{0} \int_{h^{R D *}}^{+\infty} f(x) d x+\left[v-k\left(e_{0} h^{R D *}-\Delta e\right)\right] f\left(h^{R D *}\right)\right\}\left(h^{R D *}\right)^{2}}{(v+k \Delta e) \int_{0}^{h^{R C *}} x f(x) d x+k e_{0} h^{R C *} \int_{h^{R C *}}^{+\infty} h^{R C *} f(x) d x} \geq \varphi \\
\geq \frac{(v+k \Delta e) \int_{0}^{h^{R D *}} x f(x) d x+k e_{0} h^{R D *} \int_{h^{R D *}}^{+\infty} h^{R D *} f(x) d x}{(v+k \Delta e) \int_{0}^{h^{R C *}} x f(x) d x+k e_{0} h^{R C *} \int_{h^{R C *}}^{+\infty} h^{R C *} f(x) d x}
\end{gathered}
$$




\section{Optimal Emission Reduction Level Based on Carbon Tax and Consumers' Low-Carbon Preferences under Stochastic Demand}

The final revenue of the supply chain is determined by sales revenue and production costs. On the one hand, sales revenue is determined by consumer demand and product price; with the consumers' expected demand $\int_{0}^{h} x f(x) d x+\int_{h}^{+\infty} h f(x) d x$, it can be seen that the consumers' low-carbon preferences will affect the unit price of products. On the other hand, in addition to order quantity and wholesale price, the choice of supply chain emission reduction level will also change production costs, while the supply chain will pay carbon tax for the carbon emissions generated. Since consumer's low carbon preferences and emission reduction level will affect the final revenue of supply chain from income and cost, respectively, this section will discuss the impact of lowcarbon preferences on revenue and the determination of the optimal emission reduction level of the manufacturer.

4.1. Impact of Consumers' Low-Carbon Preferences on Revenue in Supply Chain Emission Reduction. As shown in (28), the consumers' low-carbon preferences in the supply chain reduction are reflected in the product retail price $p=v-$ $k\left(e_{0} \times h-\Delta e\right)$ and the sensitivity $k$ to carbon footprint. When the manufacturer emits more carbon dioxide $e_{0} \times h-\Delta e$ per unit product, consumers who are more sensitive to the carbon footprint (the larger the $k$ value) are willing to pay less for the unit product, which ultimately has an impact on the optimal revenue of the retailer and the manufacturer. The relationship between low-carbon preferences and revenue is discussed below.

Proposition 9. In the case of emission reduction, the optimal revenue of members in the centralized supply chain is strictly monotonously decreasing with respect to consumers' lowcarbon preferences. In the decentralized supply chain, only when Condition (I) is satisfied can the retailer's optimal revenue be strictly monotonously increasing of the consumers' lowcarbon preferences. Only when Condition (II) is met can the manufacturer's optimal revenue strictly monotonously decrease with respect to consumers' low-carbon preferences.

Condition (I). It is when $\left\{2 f\left(h^{R D *}\right)+f^{\prime}\left(h^{R D *}\right) h^{R D *}\right\}>0$, and

$$
\begin{aligned}
& \left(e_{0} h^{R D *}-\Delta e\right)\left[f\left(h^{R D *}\right)\right] h^{R D *} \\
& >\int_{0}^{h^{R D *}} x f(x) d x \\
& \quad+\left(4 e_{0} h^{R D *}-\Delta e\right) \int_{h^{R D *}}^{+\infty} f(x) d x, \\
& (v+k \Delta e) h^{R D *} f\left(h^{R D *}\right)+k e_{0} 2 h^{R D *} \int_{h^{R D *}}^{+\infty} f(x) d x \\
& >k e_{0}\left(h^{R D *}\right)^{2} f\left(h^{R D *}\right) ;
\end{aligned}
$$

Condition (II). It is when $\left\{2 f\left(h^{R D *}\right)+f^{\prime}\left(h^{R D *}\right) h^{R D *}\right\}>0$, and

$$
\begin{aligned}
& \left(e_{0} h^{R D *}-\Delta e\right)\left[f\left(h^{R D *}\right)\right] h^{R D *}>\int_{0}^{h^{R D *}} x f(x) d x \\
& +\left(4 e_{0} h^{R D *}-\Delta e\right) \int_{h^{R D *}}^{+\infty} f(x) d x \\
& {\left[v-\left(e_{0} h^{R D *}-\Delta e\right)\right] f\left(h^{R D *}\right)<-2 e_{0} \int_{h^{R D *}}^{+\infty} f(x) d x,} \\
& {\left[v-k\left(e_{0} h^{R D *}-\Delta e\right)\right]} \\
& \quad \cdot\left(f^{\prime}\left(h^{R D *}\right)\left(h^{R D *}\right)^{2}+2 h^{R D *} f\left(h^{R D *}\right)\right) \\
& \left.+4 k e_{0} h^{R D *}\right]_{h^{R D *}}^{+\infty} f(x) d x<3 k e_{0} f\left(h^{R D *}\right) \\
& \quad\left(h^{R D *}\right)^{2} \cdot
\end{aligned}
$$

Proof. For the centralized supply chain, the first-order partial derivative of (39) on $k$ is

$$
\begin{aligned}
& \frac{\partial h^{R C *}}{\partial k} \\
& =\frac{e_{0} \int_{0}^{h^{R C *}} x f(x) d x+\left(2 e_{0} h^{R C *}-\Delta e\right) \int_{h^{R C *}}^{+\infty} f(x) d x}{\left[v-2 k e_{0}\right] \int_{h^{R C *}}^{+\infty} f(x) d x-\left[v-k\left(e_{0} \times h^{R C *}-\Delta e\right)\right] f\left(h^{R C *}\right)}
\end{aligned}
$$

Substituting (45) into (40), we get the first-order partial derivative on $k$ :

$$
\begin{aligned}
& \frac{\partial y_{S}^{R C *}}{\partial k}=\varphi\left[(\Delta e) \int_{0}^{h^{R C *}} x f(x) d x\right. \\
& \quad+\left(e_{0} \int_{0}^{h^{R C *}} x f(x) d x\right. \\
& \left.\left.\quad+\left(2 e_{0} h^{R C *}-\Delta e\right) \int_{h^{R C *}}^{+\infty} f(x) d x\right) h^{R C *}\right]
\end{aligned}
$$

Similarly, it can be proved that

$$
\begin{aligned}
& \frac{\partial y_{P}^{R C *}}{\partial k}=(1-\varphi)\left[(\Delta e) \int_{0}^{h^{R C *}} x f(x) d x\right. \\
& +\left(e_{0} \int_{0}^{h^{R C *}} x f(x) d x\right. \\
& \left.\left.+\left(2 e_{0} h^{R C *}-\Delta e\right) \int_{h^{R C *}}^{+\infty} f(x) d x\right) h^{R C *}\right]
\end{aligned}
$$

Since (46) and (47) are greater than zero, the manufacturer's optimal revenue is strictly monotonously increasing with respect to consumers' low-carbon preferences. Similarly, for decentralized supply chain, we have 
Mathematical Problems in Engineering

11

$$
\begin{aligned}
& \frac{\partial k}{\partial h^{R D *}} \\
& =\frac{\left[4 k e_{0}-v\right] \int_{h^{R D *}}^{+\infty} f(x) d x+\left[v-k\left(e_{0} h^{R D *}-\Delta e\right)\right] \times\left\{2 f\left(h^{R D *}\right)+f^{\prime}\left(h^{R D *}\right) h^{R D *}\right\}+\left[v-3 k\left(e_{0}\right)\right] \times\left[f\left(h^{R D *}\right)\right] h^{R D *}}{\left(e_{0} h^{R D *}-\Delta e\right)\left[f\left(h^{R D *}\right)\right] h^{R D *}-\int_{0}^{h^{R D *}} x f(x) d x-\left(4 e_{0} h^{R D *}-\Delta e\right) \int_{h^{R D *}}^{+\infty} f(x) d x} \\
& \frac{\partial y_{S}^{R D *}}{\partial k} \\
& =\Delta e \int_{0}^{h^{R D *}} x f(x) d x+e_{0}\left(h^{R D *}\right)^{2} \int_{h^{R D *}}^{+\infty} f(x) d x \\
& \quad+\frac{\partial h^{R D *}}{\partial k}\left\{(v+k \Delta e) h^{R D *} f\left(h^{R D *}\right)+k e_{0} 2 h^{R D *} \int_{h^{R D *}}^{+\infty} f(x) d x-k e_{0}\left(h^{R D *}\right)^{2} f\left(h^{R D *}\right)\right\}
\end{aligned}
$$

When the parameters satisfy $\left\{2 f\left(h^{R D *}\right)+f^{\prime}\left(h^{R D *}\right) h^{R D *}\right\}$ $>0$,

$$
\begin{aligned}
& \left(e_{0} h^{R D *}-\Delta e\right)\left[f\left(h^{R D *}\right)\right] h^{R D *}>\int_{0}^{h^{R D *}} x f(x) d x \\
& +\left(4 e_{0} h^{R D *}-\Delta e\right) \int_{h^{R D *}}^{+\infty} f(x) d x, \\
& \text { and }(v+k \Delta e) h^{R D *} f\left(h^{R D *}\right) \\
& +k e_{0} 2 h^{R D *} \int_{h^{R D *}}^{+\infty} f(x) d x>k e_{0}\left(h^{R D *}\right)^{2} f\left(h^{R D *}\right), \\
& \text { and }\left[v-k\left(e_{0} h^{R D *}-\Delta e\right)\right] \\
& \cdot\left(f^{\prime}\left(h^{R D *}\right)\left(h^{R D *}\right)^{2}+2 h^{R D *} f\left(h^{R D *}\right)\right) \\
& +4 k e_{0} h^{R D *} \int_{h^{R D *}}^{+\infty} f(x) d x<3 k e_{0} f\left(h^{R D *}\right) \\
& \cdot\left(h^{R D *}\right)^{2}
\end{aligned}
$$

$$
\begin{aligned}
& \frac{\partial y_{P}^{R D *}}{\partial k}=\left\{2 e_{0} \int_{h^{R D *}}^{+\infty} f(x) d x+\left[v-\left(e_{0} h^{R D *}-\Delta e\right)\right]\right. \\
& \left.\cdot f\left(h^{R D *}\right)\right\}\left(h^{R D *}\right)^{2} \\
& +\frac{\partial h^{R D *}}{\partial k}\left\{\left[v-k\left(e_{0} h^{R D *}-\Delta e\right)\right]\right. \\
& \cdot\left(f^{\prime}\left(h^{R D *}\right)\left(h^{R D *}\right)^{2}+2 h^{R D *} f\left(h^{R D *}\right)\right) \\
& -3 k e_{0} f\left(h^{R D *}\right)\left(h^{R D *}\right)^{2} \\
& \left.+4 k e_{0} h^{R D *} \int_{h^{R D *}}^{+\infty} f(x) d x\right\}
\end{aligned}
$$$$
\left[v-\left(e_{0} h^{R D *}-\Delta e\right)\right] f\left(h^{R D *}\right)<-2 e_{0} \int_{h^{R D *}}^{+\infty} f(x) d x,
$$

we have $\partial k / \partial h^{R D *}>0$ and $\partial y_{P}^{R D *} / \partial k<0$. Hence, the manufacture's optimal revenue is strictly monotonous decreasing with respect to consumers' low-carbon preferences.

4.2. Optimal Emission Reduction Level in the Supply Chain. Since the choice of emission reduction level in the supply chain will have an impact on the revenue of the retailer and the manufacturer, we study the optimal emission reduction level of the manufacturer as below.

Proposition 10. When the supply chain reduces emission, the optimal revenue of the retailer in the centralized (or decentralized) supply chain is strictly monotonously increasing with respect to the emission reduction level.

Proof. In the centralized supply chain, the optimal order quantity satisfies the following equation:

$$
\begin{aligned}
& \left(-k e_{0}\right)\left[\int_{0}^{h^{R C *}} x f(x) d x+\int_{h^{R C *}}^{+\infty} h^{R C *} f(x) d x\right] \\
& +\left[v-k\left(e_{0} \times h^{R C *}-\Delta e\right)\right] \int_{h^{R C *}}^{+\infty} f(x) d x \\
& =c+e_{0} t+s_{1}+s_{2}
\end{aligned}
$$


And the first-order partial derivative of (52) on $h^{R C *}$ is

$$
\begin{aligned}
& \frac{\partial h^{R C *}}{\partial \Delta e} \\
& =\frac{k \int_{h^{R C *}}^{+\infty} f(x) d x}{\left[v-k\left(e_{0} \times h^{R C *}-\Delta e\right)\right] f\left(h^{R C *}\right)+2 k e_{0} \int_{h^{R C *}}^{+\infty} f(x) d x} \\
& >0
\end{aligned}
$$

It can be seen that the optimal order quantity is strictly monotonously increasing with respect to the emission reduction level.

The first-order partial derivative of $(40)$ on $h^{R C *}$ is

$$
\begin{aligned}
& \frac{\partial y_{S}^{R C *}}{\partial h^{R C *}}=\varphi\left[k \frac{\partial \Delta e}{\partial h^{R C *}} \int_{0}^{h^{R C *}} x f(x) d x\right. \\
& +(v+k \Delta e) h^{R C *} f\left(h^{R C *}\right) \\
& +2 k e_{0} h^{R C *} \int_{h^{R C *}}^{+\infty} f(x) d x
\end{aligned}
$$

$$
\begin{aligned}
& \left.-k e_{0}\left(h^{R C *}\right)^{2} f\left(h^{R C *}\right)\right] \\
& =\varphi\left[k \frac{\partial \Delta e}{\partial h^{R C *}} \int_{0}^{h^{R C *}} x f(x) d x\right. \\
& +2 k e_{0} h^{R C *} \int_{h^{R C *}}^{+\infty} f(x) d x \\
& \left.+\left(v-k\left(e_{0} h^{R C *}-\Delta e\right)\right) h^{R C *} f\left(h^{R C *}\right)\right]>0
\end{aligned}
$$

It shows that the retailer's optimal revenue increases monotonously with respect to the optimal order quantity. Therefore, the retailer's optimal revenue is also strictly monotonously increasing with respect to the emission reduction level.

Similarly, in the decentralized supply chain, it can be deduced that

$$
\begin{aligned}
& \frac{\partial y_{S}^{R D *}}{\partial h^{R D *}}=k \frac{\partial \Delta e}{\partial h^{R D *}} \int_{0}^{h^{R D *}} x f(x) d x+k e_{0} 2 h^{R D *} \int_{h^{R D *}}^{+\infty} f(x) d x+f\left(h^{R D *}\right)\left(v-k\left(e_{0} h^{R D *}-\Delta e\right)\right) h^{R D *} \\
& \text { and } \frac{\partial h^{R D *}}{\partial \Delta e} \\
& =\frac{k\left(\int_{h^{R D *}}^{+\infty} f(x) d x-f\left(h^{R D *}\right) h^{R D *}\right)}{2 f\left(h^{R D *}\right)\left[v-k\left(e_{0} h^{R D *}-\Delta e\right)\right]+4 k e_{0} \int_{h^{R D *}}^{+\infty} f(x) d x+\left[v-k\left(e_{0} h^{R D *}-\Delta e\right)\right] f^{\prime}\left(h^{R D *}\right) h^{R D *}-3 k e_{0} f\left(h^{R D *}\right) h^{R D *}}
\end{aligned}
$$

When the parameters satisfy $f\left(h^{R D *}\right) h^{R D *} \quad>$ $\int_{h^{R D *}}^{+\infty} f(x) d x$ and

$$
\begin{array}{rl}
3 k e_{0} & f\left(h^{R D *}\right) h^{R D *} \\
> & 2 f\left(h^{R D *}\right)\left[v-k\left(e_{0} h^{R D *}-\Delta e\right)\right] \\
& +4 k e_{0} \int_{h^{R D *}}^{+\infty} f(x) d x \\
& +\left[v-k\left(e_{0} h^{R D *}-\Delta e\right)\right] f^{\prime}\left(h^{R D *}\right) h^{R D *},
\end{array}
$$

we have $\partial y_{S}^{R D *} / \partial h^{R D *}>0$ and $\partial h^{R D *} / \partial \Delta e>0$ and the retailer's optimal revenue is strictly monotonously increasing with respect to the emission reduction level.

Proposition 11. When the supply chain reduces emissions, there exists a unique optimal emission reduction level in the centralized (or decentralized) supply chain that maximizes the manufacturer's revenue.

Proof. First, the second-order partial derivative of (52) on $\Delta e$ is

$$
\frac{\partial^{2} h^{R C *}}{\partial(\Delta e)^{2}}=\frac{\partial h^{R C *}}{\partial \Delta e} \frac{-2 k f\left(h^{R C *}\right)-\left\{\left[v-k\left(e_{0} \times h^{R C *}-\Delta e\right)\right] f^{\prime}\left(h^{R C *}\right)-3 k e_{0} f\left(h^{R C *}\right)\right\}\left(\partial h^{R C *} / \partial \Delta e\right)}{\left[v-k\left(e_{0} \times h^{R C *}-\Delta e\right)\right] f\left(h^{R C *}\right)+2 k e_{0} \int_{h^{R C *}}^{+\infty} f(x) d x}
$$


Substituting (46) into (41), we get the second-order partial derivative of (41) on $\Delta e$ :

$$
\frac{\partial^{2} y_{P}^{R C *}}{\partial(\Delta e)^{2}}=\frac{(1-\varphi)\left(k \int_{h^{R C *}}^{+\infty} f(x) d x\right)^{2}-2 \gamma\left[v-k\left(e_{0} \times h^{R C *}-\Delta e\right)\right] f\left(h^{R C *}\right)-4 \gamma k e_{0} \int_{h^{R C *}}^{+\infty} f(x) d x}{\left[v-k\left(e_{0} \times h^{R C *}-\Delta e\right)\right] f\left(h^{R C *}\right)+2 k e_{0} \int_{h^{R C *}}^{+\infty} f(x) d x}
$$

In (58), since $k \int_{h^{R C *}}^{+\infty} f(x) d x<1$ and $(1-$ $\varphi)\left(k \int_{h^{R C *}}^{+\infty} f(x) d x\right)^{2}-4 \gamma k e_{0} \int_{h^{R C *}}^{+\infty} f(x) d x<0$, hence, the numerator is significantly smaller than zero. Because the price $p=\left[v-k\left(e_{0} \times h^{R C *}-\Delta e\right)\right]$ and the probability density $f\left(h^{R C *}\right)$ are both greater than zero, so the denominator is greater than zero, and we derive $\partial^{2} y_{P}^{R C *} / \partial(\Delta e)^{2}<0$. Furthermore, it can be seen that the manufacturer's revenue is a concave function of the emission reduction level. There exists a unique emission reduction level at $\partial y_{P}^{R C *} / \partial \Delta e=0$ that can maximize the manufacturer's revenue.

In the centralized supply chain, when $y_{P}^{R C *} / \partial \Delta e=0$, the optimal emission reduction level can be expressed as $\Delta e *=$ $\left((1-\varphi) k\left[\int_{0}^{h^{R C *}} x f(x) d x+h^{R C *} \int_{h^{R C *}}^{+\infty} f(x) d x\right]+t\right) / 2 \gamma$. Hence, the retailer's optimal revenue is

$$
\begin{aligned}
y_{S}^{R C *}\left(h^{R C *}, \varphi\right)=\varphi[(v+k \\
\left.\cdot \frac{(1-\varphi) k\left[\int_{0}^{h^{R C *}} x f(x) d x+h^{R C *} \int_{h^{R C *}}^{+\infty} f(x) d x\right]+t}{2 \gamma}\right)
\end{aligned}
$$

$$
\left.\cdot \int_{0}^{h^{R C *}} x f(x) d x+k e_{0} h^{R C *} \int_{h^{R C *}}^{+\infty} h^{R C *} f(x) d x\right]
$$

And the manufacturer's optimal revenue is

$$
\begin{aligned}
& y_{P}^{R C *}\left(u^{R C *}, \varphi\right)=(1-\varphi)\left[v \int_{0}^{h^{R C *}} x f(x) d x\right. \\
& \left.+k e_{0} h^{R C *} \int_{h^{R C *}}^{+\infty} h^{R C *} f(x) d x\right] \\
& \left.+\frac{(1-\varphi) k\left[\int_{0}^{h^{R C *}} x f(x) d x+h^{R C *} \int_{h^{R C *}}^{+\infty} f(x) d x\right]+t}{2 \gamma}\right] t \\
& -\gamma \frac{(1-\varphi) k\left[\int_{0}^{h^{R C *}} x f(x) d x+h^{R C *} \int_{h^{R C *}}^{+\infty} f(x) d x\right]+t}{2 \gamma} \\
& \left.+k(1-\varphi) \int_{0}^{h^{R C *}} x f(x) d x\right]
\end{aligned}
$$

Similarly, in the decentralized supply chain, we have

$$
\begin{aligned}
& \frac{\partial \Delta e}{\partial h^{R D *}} \\
& \quad=\frac{2 f\left(h^{R D *}\right)\left[v-k\left(e_{0} h^{R D *}-\Delta e\right)\right]+4 k e_{0} \int_{h^{R D *}}^{+\infty} f(x) d x+\left[v-k\left(e_{0} h^{R D *}-\Delta e\right)\right] f^{\prime}\left(h^{R D *}\right) h^{R D *}-3 k e_{0} f\left(h^{R D *}\right) h^{R D *}}{k\left(\int_{q^{R D}}^{+\infty} f(x) d x-f\left(h^{R D *}\right) h^{R D *}\right)} \\
& \frac{\partial^{2} y_{P}^{R D *}}{\partial(\Delta e)^{2}}=\frac{\partial^{2} h^{R D *}}{\partial(\Delta e)^{2}}\left\{4 k e_{0} h^{R D *} \int_{h^{R D *}}^{+\infty} f(x) d x+2 f\left(h^{R D *}\right) h^{R D *}\left[v-k\left(e_{0} h^{R D *}-\Delta e\right)\right]-3 k e_{0} h^{R D *} f\left(h^{R D *}\right) h^{R D *}\right. \\
& \left.\quad+\left[v-k\left(e_{0} h^{R D *}-\Delta e\right)\right] f^{\prime}\left(h^{R D *}\right)\left(h^{R D *}\right)^{2}\right\}+\frac{\partial h^{R D *}}{\partial \Delta e}\left\{4 k e_{0} \frac{\partial h^{R D *}}{\partial \Delta e}\left[\int_{h^{R D *}}^{+\infty} f(x) d x-h^{R D *} f\left(h^{R D *}\right)\right]\right. \\
& \quad+2 f^{\prime}\left(h^{R D *}\right) \frac{\partial h^{R D *}}{\partial \Delta e} h^{R D *}\left[v-k\left(e_{0} h^{R D *}-\Delta e\right)\right]+2 f\left(h^{R D *}\right) \frac{\partial h^{R D *}}{\partial \Delta e}\left[v-k\left(e_{0} h^{R D *}-\Delta e\right)\right] \\
& \quad+2 f\left(h^{R D *}\right) h^{R D *}\left[-k e_{0} \frac{\partial h^{R D *}}{\partial \Delta e}+k\right]-3 k e_{0} 2 h^{R D *} \frac{\partial h^{R D *}}{\partial \Delta e} f\left(h^{R D *}\right)-3 k e_{0}\left(h^{R D *}\right)^{2} f^{\prime}\left(h^{R D *}\right) \frac{\partial h^{R D *}}{\partial \Delta e} \\
& +\left[-k e_{0} \frac{\partial h^{R D *}}{\partial \Delta e}+k\right] f^{\prime}\left(h^{R D *}\right)\left(h^{R D *}\right)^{2}+\left[v-k\left(e_{0} h^{R D *}-\Delta e\right)\right] f^{\prime \prime}\left(h^{R D *}\right) \frac{\partial h^{R D *}}{\partial \Delta e}\left(h^{R D *}\right)^{2} \\
& \left.+\left[v-k\left(e_{0} h^{R D *}-\Delta e\right)\right] f^{\prime}\left(h^{R D *}\right) 2 h^{R D *} \frac{\partial h^{R D *}}{\partial \Delta e}\right\}+k f^{\prime}\left(h^{R D *}\right) \frac{\partial h^{R D *}}{\partial \Delta e}\left(h^{R D *}\right)^{2}+k f\left(h^{R D *}\right) 2 h^{R D *} \frac{\partial h^{R D *}}{\partial \Delta e}-2 \gamma
\end{aligned}
$$


When the parameters satisfy

$$
\begin{aligned}
& 2 f\left(h^{R D *}\right)\left[v-k\left(e_{0} h^{R D *}-\Delta e\right)\right]+4 k e_{0} \int_{h^{R D *}}^{+\infty} f(x) d x+\left[v-k\left(e_{0} h^{R D *}-\Delta e\right)\right] f^{\prime}\left(h^{R D *}\right) h^{R D *} \\
& \quad-3 k e_{0} f\left(h^{R D *}\right) h^{R D *}>0 \\
& \text { and } \frac{\partial^{2} h^{R D *}}{\partial(\Delta e)^{2}}\left\{\begin{array}{l}
4 k e_{0} h^{R D *} \int_{h^{R D *}}^{+\infty} f(x) d x+2 f\left(h^{R D *}\right) h^{R D *}\left[v-k\left(e_{0} h^{R D *}-\Delta e\right)\right] \\
-3 k e_{0} h^{R D *} f\left(h^{R D *}\right) h^{R D *}+\left[v-k\left(e_{0} h^{R D *}-\Delta e\right)\right] f^{\prime}\left(h^{R D *}\right)\left(h^{R D *}\right)^{2}
\end{array}\right\}<0,
\end{aligned}
$$

we have $\partial h^{R D *} / \partial \Delta e<0, \partial^{2} y_{P}^{R D *} / \partial(\Delta e)^{2}<0$, and the manufacturer's revenue is a concave function of the emission reduction level. When $\partial y_{P}^{R D *} / \partial \Delta e=0$, there is a unique optimal emission reduction level that can maximize the manufacturer's revenue.

\section{Simulation Analysis}

In this section, we present a simulation analysis to show how our analysis works under the stated assumptions. Firstly, this paper analyzes the relationship between consumers' lowcarbon preferences and the revenue of supply chain members. Then it discusses the impact of government's punitive measures on the manufacturer's emission reduction level and compares the decision process of centralized supply chain and decentralized supply chain with emission reduction. Furthermore, it studies the mechanism of emission reduction level on the revenue sharing coefficient in the centralized supply chain and finally explores the impact of carbon tax and consumers' low-carbon preferences on the optimal emission reduction level in the centralized supply chain. Referring to the study by $\mathrm{Du}$ et al. [13], we solve the problem with the proposed model in which $k=0.5, e_{0}=0.2, v=200, s_{1}+s_{2}=10$, $c=35, t=10, \gamma=10, \eta=0.1, \xi \sim N\left(150,10^{2}\right)$.

\subsection{Impact of Consumers' Low-Carbon Preferences on the Rev-} enue of Supply Chain Members. With the growing popularity of environmental consciousness, consumers are willing to pay more for low-carbon products. As can be seen from $p=v-k\left(e_{0} \times h-\Delta e\right)$ of (28), the more carbon dioxide $e_{0} \times h-\Delta e$ emitted by the manufacturer to produce a unit product, the lower the purchase price that consumers are willing to pay. Consumers' low-carbon preferences are also reflected in the sensitivity to the carbon footprint, the more sensitive to the carbon footprint, the greater the impact of carbon emissions on product prices. Consumers' low-carbon preferences will affect the manufacturer's optimal wholesale price, the retailer's optimal order quantity, and the product retail price and ultimately has an impact on the optimal revenue of the retailer and the manufacturer. According to (33), (34), (40), and (41), we present the relationships among product retail price, optimal revenue of supply chain members, and consumers' low-carbon preferences for the decentralized supply chain and centralized supply chain, as shown in Figures 1-6

In Figures 1-6, the horizontal axis represents the consumers' low-carbon preferences, and the vertical axis represents the product retail price or supply chain members' revenue. It can be seen that, in the decentralized supply chain, when other parameters are given, the product retail price and the optimal revenue of the manufacturer are all strictly monotonously decreasing with respect to consumers' low-carbon preferences, while the optimal revenue of the retailer is strictly monotonously increasing on the consumers' low-carbon preferences. In the centralized supply chain, the product retail price and the optimal revenue of members are strictly monotonously decreasing on the consumers' low-carbon preferences. The relationships between the consumers' low-carbon preferences and the revenue of supply chain members that reflected in Figures 1-6 are consistent with Proposition 9.

\subsection{Analysis of the Impact of Government's Punitive Measures} on Manufacturer's Emission Reduction Level. According to (1), (2), (28), and (29), we obtain the figures (Figures 7-10), which show the impact of wholesale price and emission reduction level on the revenue of the manufacturer and the retailer in the centralized and decentralized supply chain under the conditions of emission reduction and nonreduction, respectively. And we further analyze the impact of the government's punitive measures on the emission reduction level of the manufacturer. In Figures $7-10$, the $x$-axis represents the wholesale price $w$, the $y$-axis denotes the emission reduction level $\Delta e$, and the $z$-axis represents the revenue $y$. The surface illustrates the change in the revenue of both the manufacturer and the retailer when the supply chain reduces emissions, and the curve shows the change in the revenue of both parties with no-reducing emissions (when the emission reduction level is 0 ).

As can be seen from Figure 7, for a decentralized supply chain, the manufacturer's revenue increases first and then decreases as the wholesale price increases. At the given level of emission reduction, there is always an optimal wholesale price that can maximize the manufacturer's revenue. As the emission reduction level increases, the manufacturer's revenue rises first and then decreases, but it is not as obvious as the case of the wholesale price changes. When the wholesale 


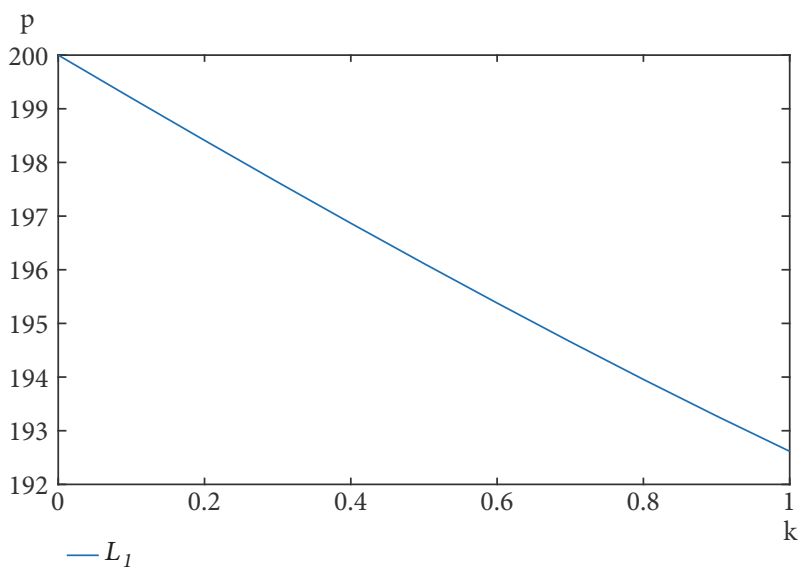

FIGURE 1: Impact of consumers' low carbon preferences on product retail price in decentralized supply chain.

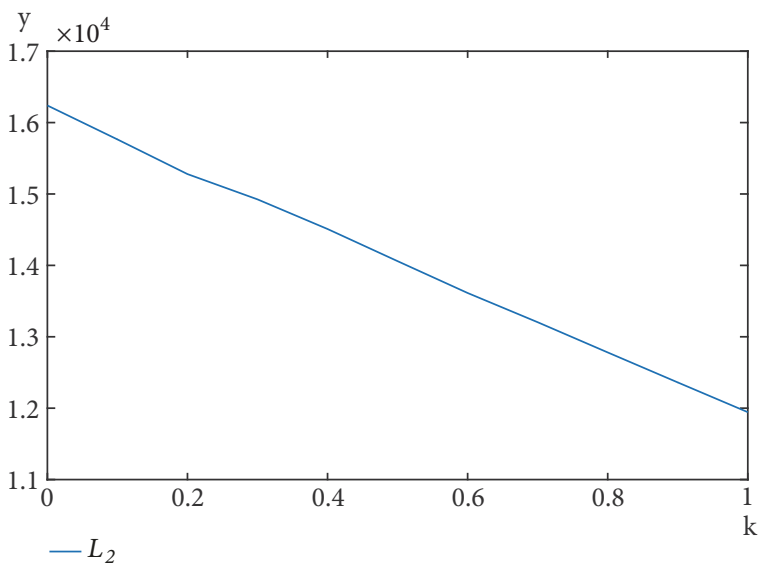

FIGURE 2: Impact of consumers' low carbon preferences on manufacturer's optimal revenue in decentralized supply chain.

price is given, there is always an optimal emission reduction level that can maximize the manufacturer's revenue. In the decentralized supply chain of Figure 8 , the retailer's revenue decreases as the wholesale price increases. When the manufacturer's emission reduction level is getting larger, the retailer's revenue is slowly increasing, but it does not show the significant characteristics like the manufacturer's revenue changes with the emission reduction level. In Figure 7, the curve $L_{1}$ is far away from the surface $y_{p}$, indicating that the manufacturer's revenue changes greatly before and after emission reduction. In Figure 8, the curve $L_{2}$ is closer to the surface $y_{s}$, which indicates that the change of the retailer's revenue is small before and after the emission reduction. The results of Figures 7 and 8 show that the manufacturer's revenue changes more significantly than the retailer's. This is because the manufacturer will change the wholesale price when taking emission reduction measures, so that it can directly obtain most of the revenue from emission reduction, and the retailer does not need to take any measures, so its revenue is less.

As can be seen from Figures 9 and 10, in the centralized supply chain, the impact of emission reduction level and

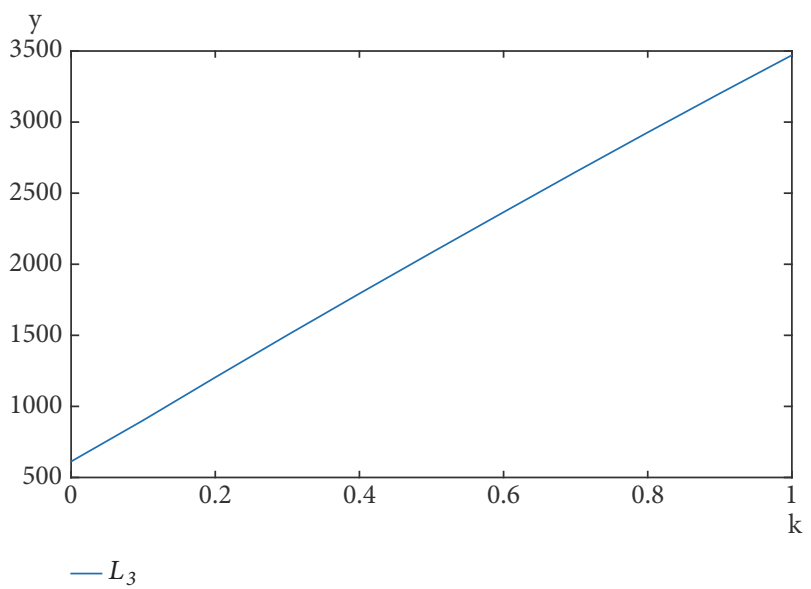

FIGURE 3: Impact of consumers' low carbon preferences on retailer's optimal revenue in decentralized supply chain.

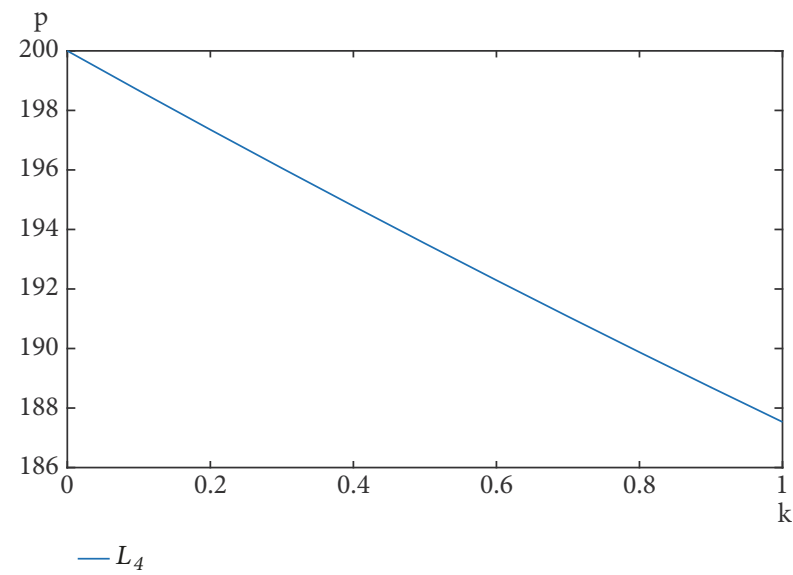

FIGURE 4: Impact of consumers' low carbon preferences on product retail price in centralized supply chain.

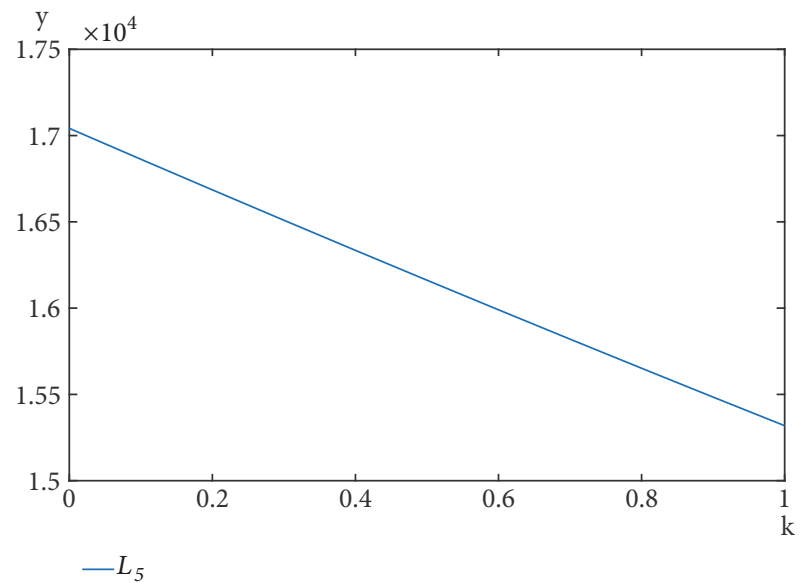

FIGURE 5: Impact of consumers' low carbon preferences on manufacturer's optimal revenue in centralized supply chain.

wholesale price on the revenue of supply chain members is basically the same as that of decentralized supply chain, and the manufacturer get more revenue from the retailer 


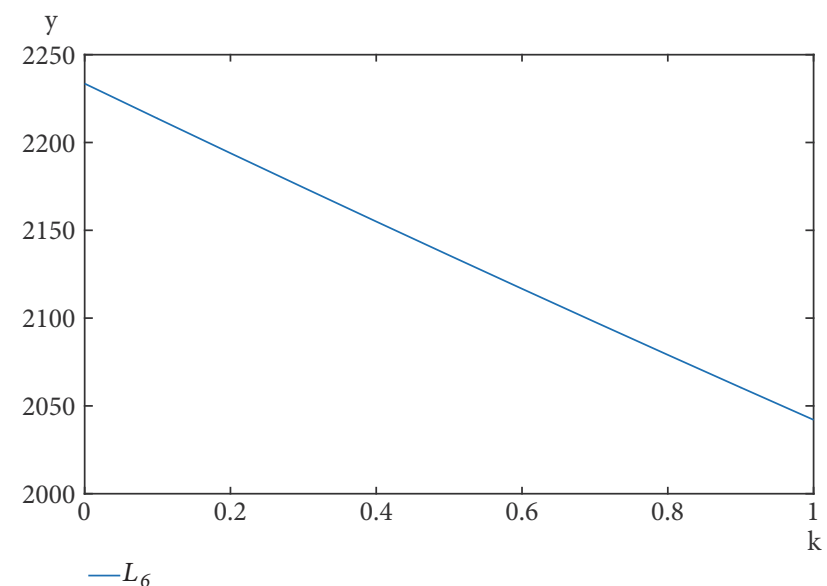

FIGURE 6: Impact of consumers' low carbon preferences on retailer's optimal revenue in centralized supply chain.

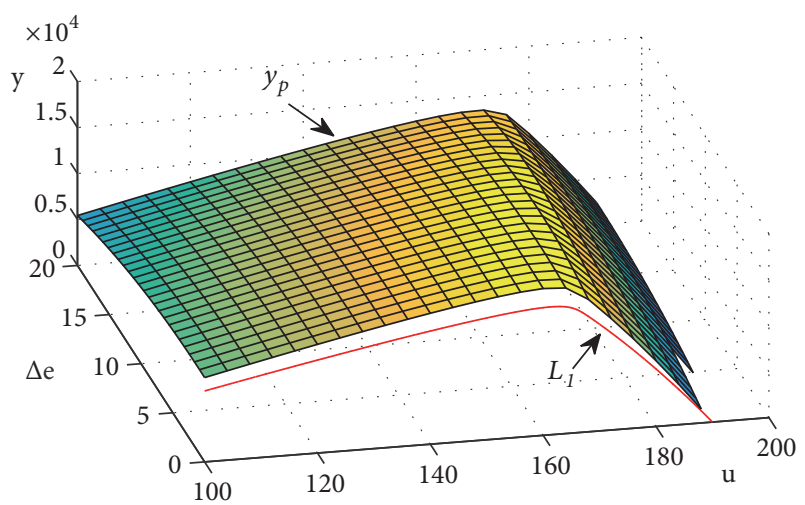

FIGURE 7: Impact of wholesale price and emission reduction level on manufacturer's revenue in decentralized supply chain.

through a revenue sharing contract. We further find that if the government applies the punitive measures and the manufacturer does not reduce emissions, the revenue of the supply chain members will appear as a curve in the figure. Furthermore, the curves in Figures 7-10 are always below the surfaces because the government takes punitive measures against the manufacturer. When the manufacturer does not reduce emissions, the government will impose fines on the manufacturer, thus reducing the overall revenue of the retailer and the manufacturer. Therefore, when introducing a penalty mechanism, emission reduction is the optimal choice for the supply chain. Furthermore, the relationships among the wholesale price, emission reduction level, and the revenue of supply chain members shown in Figures 7-10 are consistent with Propositions 7, 8, 10, and 11.

5.3. Comparison of the Revenue of Supply Chain Members in the Decentralized and Centralized Supply Chain under Different Emission Reduction Level. The manufacturer proposes the emission reduction level and the optimal wholesale price, and the retailer accordingly selects the optimal order quantity. From (33), (34), (40), and (41), we can get the results of

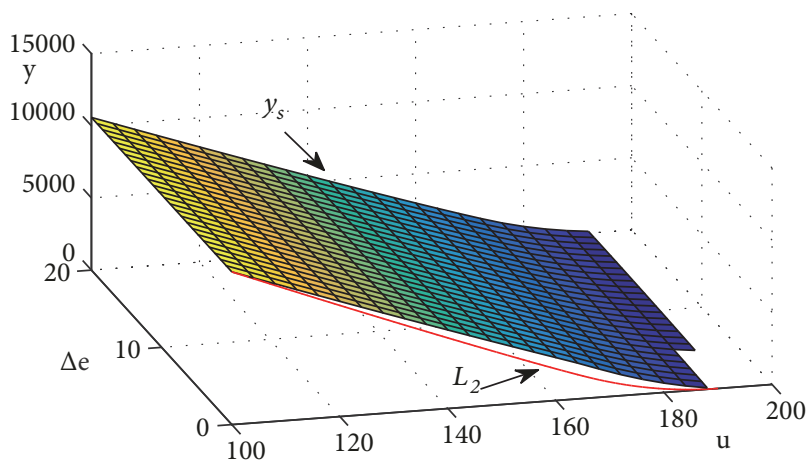

FIGURE 8: Impact of wholesale price and emission reduction level on retailer's revenue in decentralized supply chain.

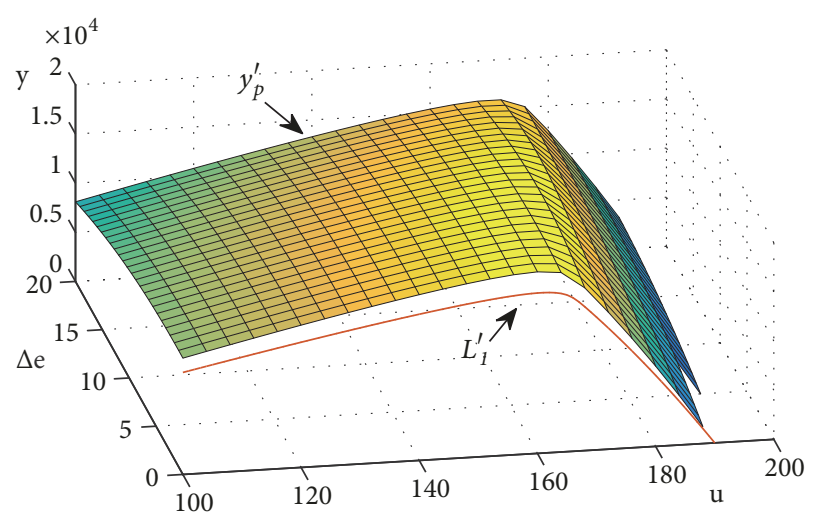

FIGURE 9: Impact of wholesale price and emission reduction level on manufacturer's revenue in centralized supply chain.

the optimal revenue of the retailer and the manufacturer with the changes of the emission reduction level in the centralized and decentralized supply chain. Let $\Delta y_{S}=$ $y_{S}^{R C *}(\Delta e)-y_{S}^{R D *}(\Delta e), \Delta y_{P}=y_{P}^{R C *}(\Delta e)-y_{P}^{R D *}(\Delta e)$ denote the change of the manufacturer's revenue and the retailer's revenue, respectively, and the curves $L_{3}, L_{4}$ in Figure 11 can be obtained as a result of the changes of the optimal revenue with the emission reduction level $\Delta e$.

In Figure 11, the horizontal axis represents the emission reduction level $\Delta e$ and the vertical axis denotes the revenue increase $\Delta y$. The solid line $L_{3}$ represents the increase of the manufacturer's revenue in the centralized supply chain relative to the revenue of the decentralized supply chain, and the increase of the revenue at the left end of $L_{3}$ is large, but the slope is small. This is because the manufacturer obtains a large gain in revenue after the emission reduction due to the penalty of not paying the emission reduction. The dotted line $L_{4}$ indicates the increase of the retailer's revenue in the centralized supply chain relative to the revenue of the decentralized supply chain, and the increase of the revenue at the left end of $L_{4}$ is small, but the slope is large. The reason is that the retailer does not participate in emission reduction, but only shares the revenue of the manufacturer's emission reduction. Both $L_{3}$ and $L_{4}$ are above the horizontal axis, and the increments of revenue increases as the emission 


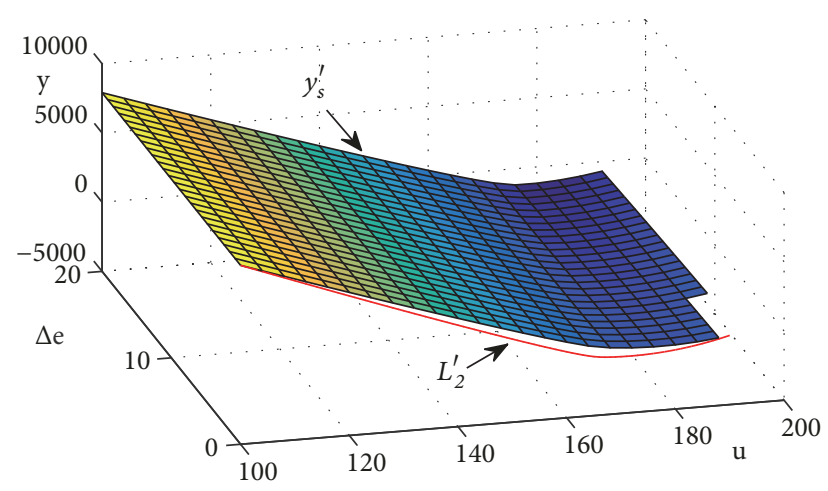

FIGURE 10: Impact of wholesale price and emission reduction level on retailer's revenue in centralized supply chain.

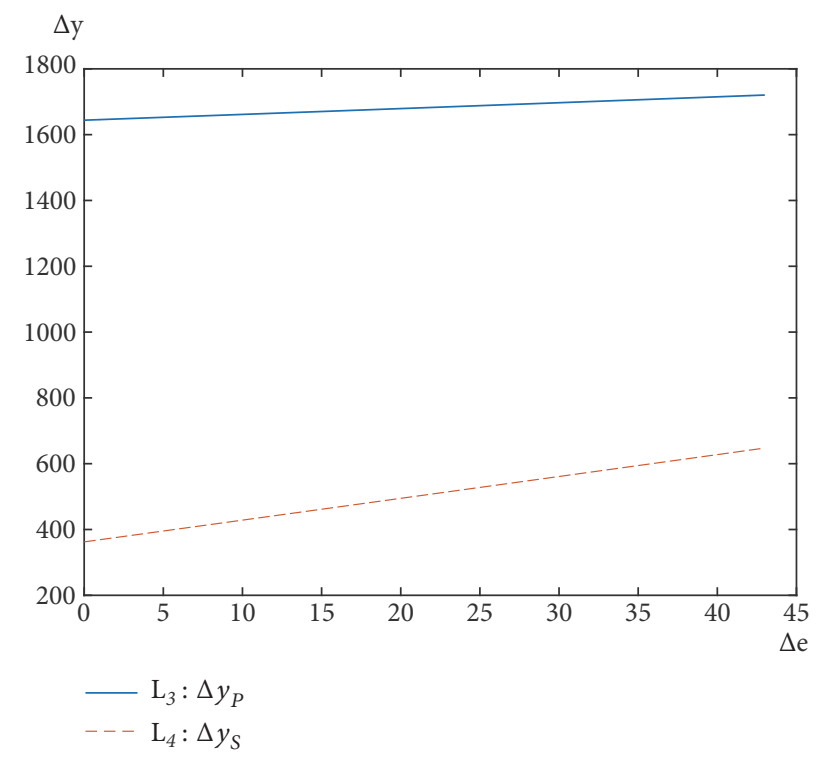

FIGURE 11: Impact of emission reduction level on the increase in revenue of supply chain members.

reduction level rises. It shows that when adopting emission reduction measures, the centralized supply chain is better than the decentralized supply chain, which is consistent with the incentive mechanism of the revenue sharing contract.

\subsection{Impact of Changes in Emission Reduction Level on the} Revenue Sharing Coefficient under Centralized Supply Chain. In the centralized supply chain, the manufacturer and the retailer reach the revenue sharing contract. Only when the revenue sharing coefficient $\varphi$ is within a reasonable range, the benefits of the retailer and the manufacturer are greater than that of the decentralized supply chain. If $\varphi$ in the revenue sharing contract is not within its reasonable range, then the supply chain members cannot obtain higher benefits than the decentralized supply chain, and the centralized supply chain will lose its meaning. The determination of the reasonable range of the revenue sharing coefficient is an important part of the centralized supply chain. Therefore, this section will analyze the range of the revenue sharing coefficient. It is assumed that the lower limit of $\varphi$ is $a$, and the upper limit of $\varphi$ is $b$; carbon tax $t$ is taken as $t=10,20$, and 30 , respectively; consumers' low-carbon preferences $k$ is taken as $k=0.1,0.5$, and 0.9 ; the emission reduction level $\Delta e$ is taken as $\Delta e=0,10,20,30$, and 40 , respectively. Based on the above assumptions and the values of each indicator, we examine the reasonable range of the revenue sharing coefficient $\varphi$ under different carbon tax $t$, consumers' low-carbon preferences $k$, and emission reduction level $\Delta e$, as shown in Table 2. According to the changes of the lower limit $a$ and upper limit $b$, we firstly analyze the impact of carbon tax, consumers' low-carbon preferences and emission reduction level on the range of the revenue sharing coefficient, respectively, and then analyze the influence mechanism of the three variables and their interaction with the range of $\varphi$.

For every 10-unit increase in emission reduction level, when $k=0.1$, the lower limit of the revenue sharing coefficient will be expanded by about $0.2 \%$, and the upper limit will be increased by about 0.0002 ; when $k=0.5$, the lower limit of $\varphi$ will be expanded by about $2 \%$, and the upper limit will be increased by about 0.01 ; when $k=0.9$, the lower limit of $\varphi$ will be expanded by about 6\%, and the upper limit will be increased by about 0.02 . This shows that the increase in consumers' low-carbon preferences will amplify the impact of changes in emission reduction level on the range of revenue sharing coefficient. In addition, as can be seen from Table 2, for every 10 units increase in carbon tax, when $k=0.1,0.5,0.9$, the lower limit of the revenue sharing coefficient will be reduced by about $0.5 \%, 1 \%, 1.2 \%$, and the upper limit will be reduced by about $0.0001,0.003,0.006$, indicating that when the consumers' low-carbon preferences increase, the impact of the carbon tax on the revenue sharing coefficient will be amplified. Moreover, Table 2 also shows that as the emission reduction level increases, the lower limit of the revenue sharing coefficient becomes smaller and the upper limit becomes larger, which indicates that, with the increase of emission reduction level, supply chain members have more negotiation space to adopt the revenue sharing mechanism, and the probability for successful negotiation is greater. However, when the consumer's low-carbon preferences increase, the upper limit of $\varphi$ becomes smaller and the lower limit gradually becomes larger, suggesting that, with the increase of consumers' low-carbon preferences, the range of revenue sharing coefficient can be smaller and smaller, and the negotiation is more difficult. When the carbon tax increases, the upper limit of $\varphi$ becomes smaller and the lower limit gradually becomes larger. Therefore, for the centralized supply chain, the government should pay attention to the impact of the carbon tax on the reasonable range of the revenue sharing coefficient when formulating the carbon tax policy.

5.5. Impact of Carbon Tax and Consumers' Low-Carbon Preferences on Optimal Emission Reduction Level in the Centralized Supply Chain. From the previous analysis, it is known that for supply chain members, emission reduction is better than no emission reduction, and the centralized supply chain is better than decentralized supply chain. Consumers' low-carbon 
TABLE 2: Effect of carbon tax and consumers' low-carbon preferences on the reasonable range of the revenue sharing coefficient under different emission reduction level.

\begin{tabular}{|c|c|c|c|c|c|c|}
\hline \multicolumn{7}{|c|}{$t=10$} \\
\hline & \multicolumn{2}{|c|}{$k=0.1$} & \multicolumn{2}{|c|}{$k=0.5$} & \multicolumn{2}{|c|}{$k=0.9$} \\
\hline$\Delta e$ & $a$ & $b$ & $a$ & $b$ & $a$ & $b$ \\
\hline 0 & 0.0413 & 0.8217 & 0.1019 & 0.6353 & 0.1708 & 0.4202 \\
\hline 10 & 0.0412 & 0.8219 & 0.0994 & 0.6430 & 0.1618 & 0.4483 \\
\hline 20 & 0.0411 & 0.8221 & 0.0970 & 0.6502 & 0.1539 & 0.4731 \\
\hline 30 & 0.0410 & 0.8224 & 0.0948 & 0.6569 & 0.1468 & 0.4950 \\
\hline 40 & 0.0410 & 0.8226 & 0.0927 & 0.6632 & 0.1404 & 0.5146 \\
\hline \multicolumn{7}{|c|}{$t=20$} \\
\hline & \multicolumn{2}{|c|}{$k=0.1$} & \multicolumn{2}{|c|}{$k=0.5$} & \multicolumn{2}{|c|}{$k=0.9$} \\
\hline$\Delta e$ & $a$ & $b$ & $a$ & $b$ & $a$ & $b$ \\
\hline 0 & 0.0415 & 0.8216 & 0.1029 & 0.6323 & 0.1730 & 0.4137 \\
\hline 10 & 0.0414 & 0.8218 & 0.1003 & 0.6403 & 0.1637 & 0.4426 \\
\hline 20 & 0.0413 & 0.8221 & 0.0979 & 0.6476 & 0.1555 & 0.4681 \\
\hline 30 & 0.0412 & 0.8223 & 0.0956 & 0.6545 & 0.1483 & 0.4906 \\
\hline 40 & 0.0411 & 0.8225 & 0.0935 & 0.6610 & 0.1418 & 0.5107 \\
\hline \multicolumn{7}{|c|}{$t=30$} \\
\hline & \multicolumn{2}{|c|}{$k=0.1$} & \multicolumn{2}{|c|}{$k=0.5$} & \multicolumn{2}{|c|}{$k=0.9$} \\
\hline$\Delta e$ & $a$ & $b$ & $a$ & $b$ & $a$ & $b$ \\
\hline 0 & 0.0416 & 0.8215 & 0.1040 & 0.6293 & 0.1752 & 0.4071 \\
\hline 10 & 0.0415 & 0.8217 & 0.1013 & 0.6374 & 0.1656 & 0.4368 \\
\hline 20 & 0.0414 & 0.8219 & 0.0988 & 0.6450 & 0.1572 & 0.4629 \\
\hline 30 & 0.0413 & 0.8222 & 0.0965 & 0.6521 & 0.1498 & 0.4861 \\
\hline 40 & 0.0413 & 0.8224 & 0.0943 & 0.6587 & 0.1431 & 0.5067 \\
\hline
\end{tabular}

Note: - indicates that the data does not satisfy the condition and is null.

preferences and government-developed carbon tax policy, which we mainly focus on in this section, have important impacts on the emission reduction level. The relationships among carbon tax, consumers' low-carbon preferences, and emission reduction level according to (40) are illustrated in Figures 12 and 13.

In Figure 12, the horizontal axis represents the emission reduction level, and the vertical axis denotes the revenue of the centralized supply chain with emission reduction. While the consumers' low-carbon preferences are given, the three curves, respectively, indicate the overall revenue of the supply chain when the carbon tax $t=10,20$, and 30 . It can be seen that there is always a maximum point on each curve; hence, when the consumers' low-carbon preferences are given, there exists an optimal emission reduction level that can maximize the overall revenue of the supply chain. In addition, as the carbon tax increases, the revenue curve changes from $L_{5}$ to $L_{7}$, and the optimal emission reduction level becomes larger and larger. This shows that the government's appropriate increase in carbon tax will promote the manufacturer to reduce emissions.

In Figure 13, when the carbon tax is given, the three curves represent the change in the overall revenue of the supply chain with emission reduction level when $k=0.1,0.5$, and 0.9. It can be seen that there exists a maximum point on each curve. Therefore, when the carbon tax is given, there is

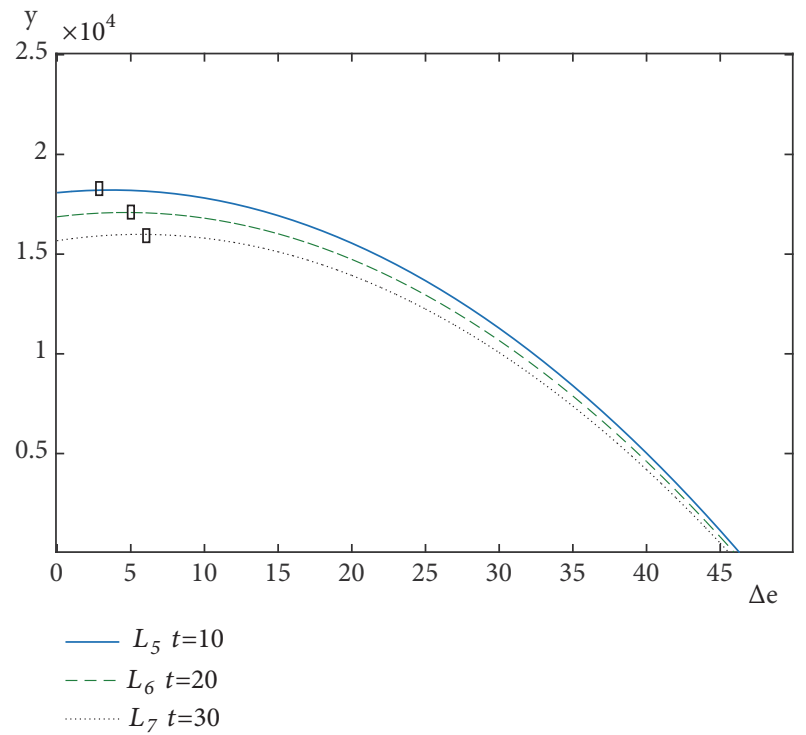

FIGURE 12: Impact of carbon tax on optimal emission reduction level with given consumers' low-carbon preferences.

an optimal emission reduction level to maximize the overall revenue of the supply chain. Furthermore, as consumers' lowcarbon preferences increase, the curve changes from $L_{8}$ to 


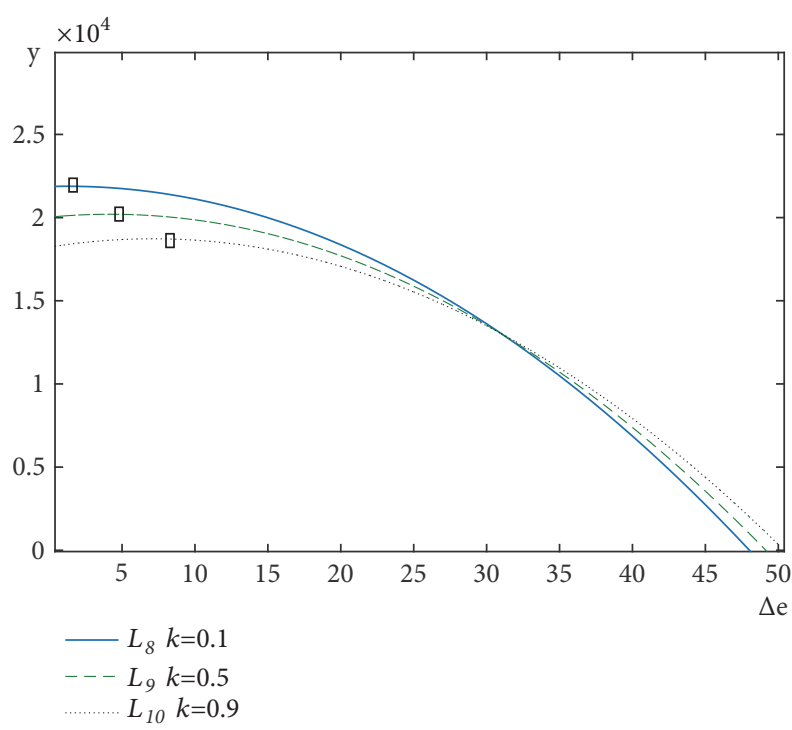

FIGURE 13: Impact of consumers' low-carbon preferences on emission reduction level with given carbon tax.

$L_{10}$, and the optimal emission reduction level is increasing. It indicates that, with the increase of consumers' low-carbon preferences, the supply chain will improve the emission reduction level.

\section{Conclusion}

This paper focuses on the emission reduction level of supply chain, taking into account consumers' low-carbon preferences, stochastic market demand, and carbon tax policy. Firstly, it constructs a function of retail price on consumers' low-carbon preferences and emission reduction level, which avoids the research flaws caused by the constant retail price, and accords with the fact that consumers with low-carbon preferences are willing to pay more for low-carbon products. Secondly, by introducing the penalty mechanism of emission reduction and using the reverse derivation method, this paper derives four revenue models of the retailer and the manufacturer in decentralized and centralized supply chain under stochastic market demand. Thirdly, it investigates the optimal emission reduction level of supply chain based on carbon tax and consumers' low-carbon preferences under stochastic demand through mathematical modeling and also takes simulation analysis. The numerical results provide important organizational and policy insights on the following. (i) In the decentralized supply chain, the manufacturer's (or the retailer's) optimal revenue is strictly monotonously decreasing (or increasing) with respect to consumers' lowcarbon preferences. In the centralized supply chain, the optimal revenue of the retailer or manufacturer is strictly monotonously decreasing with respect to consumers' lowcarbon preferences. (ii) The retailer's revenue is a concave function of the order quantity, and there exists a unique order quantity that maximizes the retailer's revenue. The manufacturer's revenue is a concave function of the wholesale price, and there exists a unique wholesale price that maximizes the manufacturer's revenue. (iii) Under the influence of penalties, the manufacturer with emission reduction will bring excess benefits to supply chain members. Furthermore, the revenue sharing contract will increase the benefits of manufacturer and retailer in the centralized supply chain, which is better than the decentralized supply chain. (iv) When consumers' low-carbon preferences are constant, there is an optimal emission reduction level that maximizes the overall revenue of the supply chain. As the carbon tax increases, the optimal emission reduction level gradually increases, which indicates that the government's appropriate increase in carbon tax can stimulate the manufacturer to reduce emissions. (v) When the carbon tax is given, the optimal emission reduction level of the supply chain is improved as the consumer's low-carbon preferences increases. (vi) With the increase of emission reduction level, the range of the revenue sharing coefficient becomes wider and wider, and it is easier for supply chain members to reach a revenue sharing contract. However, when consumers' low-carbon preferences and carbon tax increase, the opposite is true.

Due to space limitations, there are still some deficiencies in this paper. Firstly, this study only considers the emission reduction under the secondary supply chain mechanism of the retailer and the manufacturer, but does not study the overall carbon emission reduction from the multilevel supply chain system composed of suppliers, manufacturers, retailers and consumers. Secondly, this study does not consider the dynamic game problem in the emission reduction of the retailer and the manufacturer, so it does not explore the evolutionary stabilization strategy of the members' emission reduction input behavior. In addition, it only considers the consumers' low-carbon preferences, but in practice, the channel preference of the consumer is also a key factor affecting market demand and price. Therefore, we believe that under the multilevel supply chain system, considering the multiple preferences of consumers and introducing dynamic game methods to deeply explore the emission reduction level of supply chain will become a new research field in the future.

\section{Data Availability}

The authors declare that the data will be available upon acceptance of this article. The data used to support the findings of this study are included within the article; it is true and reliable. If readers need related data, they can contact us.

\section{Conflicts of Interest}

The authors declare that there are no conflicts of interest regarding the publication of this paper.

\section{Acknowledgments}

This work was supported by the National Natural Science Foundation of China under Grant no. 71171155, Xi'an Social Sciences Planning Fund major projects under Grant no. 17J92, Special Scientific Research Project of Education Department of Shaanxi Province under Grant nos. 18JK0535 
and 16JK1527, Xian Development and Reform Commission Regional Economic Issues under Grant no. SXTY2018-08-15, and Humanities and Social Sciences Research Planning Fund of Ministry of Education under Grant no. 19YJA630080.

\section{References}

[1] A. Nagurney, Z. Liu, and T. Woolley, "Optimal endogenous carbon taxes for electric power supply chains with power plants," Mathematical and Computer Modelling, vol. 44, no. 910, pp. 899-916, 2006.

[2] D. Gros, P. Lane, S. Langfield et al., "Too late, too sudden: Transition to a low-carbon economy and systemic risk," European Systemic Risk Board Report of the Advisory Scientific Committee, 2016.

[3] J. Xie, H. Dai, Y. Xie, and L. Hong, "Effect of carbon tax on the industrial competitiveness of Chongqing, China," Energy for Sustainable Development, vol. 47, pp. 114-123, 2018.

[4] L. Ibanez and G. Grolleau, "Can ecolabeling schemes preserve the environment?" Environmental and Resource Economics, vol. 40, no. 2, pp. 233-249, 2008.

[5] Q. Wang, D. Zhao, and L. He, "Contracting emission reduction for supply chains considering market low-carbon preference," Journal of Cleaner Production, vol. 120, no. 1, pp. 72-84, 2016.

[6] D. B. Marron and E. J. Toder, "Tax policy issues in designing a carbon tax," American Economic Review, vol. 104, no. 104, pp. 563-568, 2015.

[7] G. E. Metcalf, "Market-based policy options to control u.s. greenhouse gas emissions," Journal of Economic Perspectives (JEP), vol. 23, no. 2, pp. 5-27, 2009.

[8] X. Chen and G. Hao, "Sustainable pricing and production policies for two competing firms with carbon emissions tax," International Journal of Production Research, vol. 53, no. 21, pp. 1-13, 2014.

[9] D. Xiang and C. Lawley, "The impact of British Columbia's carbon tax on residential natural gas consumption," Energy Economics, vol. 80, pp. 206-218, 2019.

[10] S. Ding, M. Zhang, and Y. Song, "Exploring China's carbon emissions peak for different carbon tax scenarios," Energy Policy, vol. 129, pp. 1245-1252, 2019.

[11] Y. Liu and Y. Y. Lu, "The economic impact of different carbon tax revenue recycling schemes in China: a model-based scenario analysis," Applied Energy, vol. 141, no. 1, pp. 96-105, 2015.

[12] X. Zhao, J. Yao, C. Sun, and W. Pan, "Impacts of carbon tax and tradable permits on wind power investment in China," Journal of Renewable Energy, vol. 135, pp. 1386-1399, 2019.

[13] S. Du, J. Zhu, H. Jiao, and W. Ye, "Game-theoretical analysis for supply chain with consumer preference to low carbon," International Journal of Production Research, vol. 53, no. 12, pp. 3753-3768, 2015.

[14] Z. G. Tao, Z. Y. Guang, S. Hao, H. J. Song, and D. G. Xin, "Multi-period closed-loop supply chain network equilibrium with carbon emission constraints," Resources, Conservation \& Recycling, vol. 104, pp. 354-365, 2015.

[15] Z. Luo, X. Chen, and X. Wang, "The role of co-opetition in low carbon manufacturing," European Journal of Operational Research, vol. 253, no. 2, pp. 392-403, 2016.

[16] N. D. Rao, B. J. Van Ruijven, K. Riahi, and V. Bosetti, "Improving poverty and inequality modelling in climate research," Nature Climate Change, vol. 7, no. 12, pp. 857-862, 2017.
[17] K. Cao, X. Xu, Q. Wu, and Q. Zhang, "Optimal production and carbon emission reduction level under cap-and-trade and low carbon subsidy policies," Journal of Cleaner Production, vol. 167, pp. 505-513, 2017.

[18] S. R. Madani and M. Rasti-Barzoki, "Sustainable supply chain management with pricing, greening and governmental tariffs determining strategies: a game-theoretic approach," Computers \& Industrial Engineering, vol. 105, pp. 287-298, 2017.

[19] D. F. Drake, P. R. Kleindorfer, and L. N. Van Wassenhove, "Technology choice and capacity portfolios under emissions regulation," Production Engineering Research and Development, vol. 25, no. 6, pp. 1006-1025, 2016.

[20] B. Fahimnia, J. Sarkis, A. Choudhary, and A. Eshragh, “Tactical supply chain planning under a carbon tax policy scheme: a case study," International Journal of Production Economics, vol. 164, pp. 206-215, 2015.

[21] X. Chen, Z. Luo, and X. Wang, "Impact of efficiency, investment, and competition on low carbon manufacturing," Journal of Cleaner Production, vol. 143, pp. 388-400, 2017.

[22] S. Benjaafar, Y. Li, and M. Daskin, "Carbon footprint and the management of supply chains: insights from simple models," IEEE Transactions on Automation Science and Engineering, vol. 10, no. 1, pp. 99-116, 2012.

[23] D. Ghosh and J. Shah, "Supply chain analysis under green sensitive consumer demand and cost sharing contract," International Journal of Production Economics, vol. 164, pp. 319-329, 2015.

[24] W. Yu and R. Han, "Coordinating a two-echelon supply chain under carbon tax," Sustainability, vol. 9, no. 12, Article ID 2360, 2017.

[25] S. Shewmake, A. Okrent, L. Thabrew, and M. Vandenbergh, "Predicting consumer demand responses to carbon labels," Ecological Economics, vol. 119, pp. 168-180, 2015.

[26] L. Xia, W. Hao, J. Qin, F. Ji, and X. Yue, "Carbon emission reduction and promotion policies considering social preferences and consumers' low-carbon awareness in the cap-and-trade system," Journal of Cleaner Production, vol. 195, pp. 1105-1124, 2018.

[27] Z. Liuabc, "Consumer environmental awareness and competition in two-stage supply chains," European Journal of Operational Research, vol. 218, no. 3, pp. 602-613, 2012.

[28] C.-M. Shuai, L.-P. Ding, Y.-K. Zhang, Q. Guo, and J. Shuai, "How consumers are willing to pay for low-carbon products? - results from a carbon-labeling scenario experiment in China," Journal of Cleaner Production, vol. 83, no. 83, pp. 366-373, 2014. 


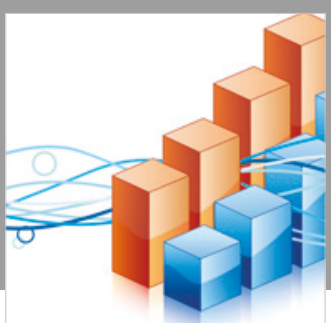

Advances in

Operations Research

\section{-n-m}
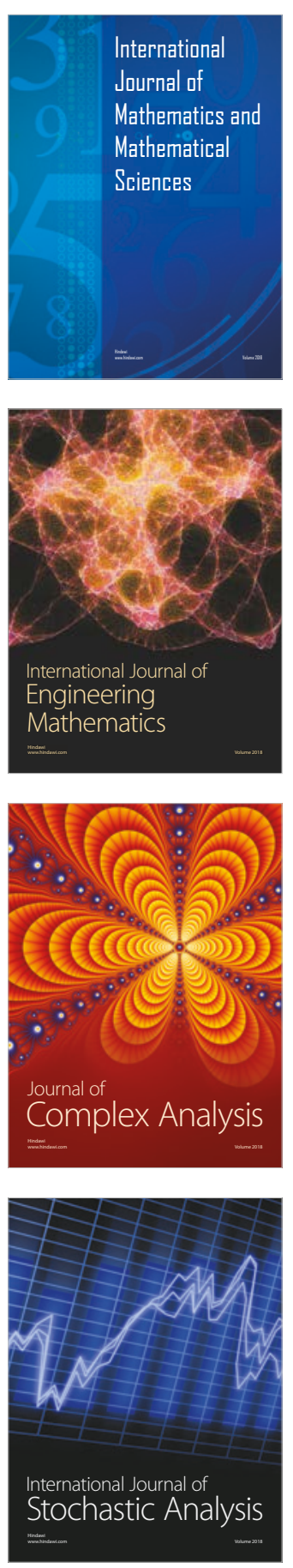
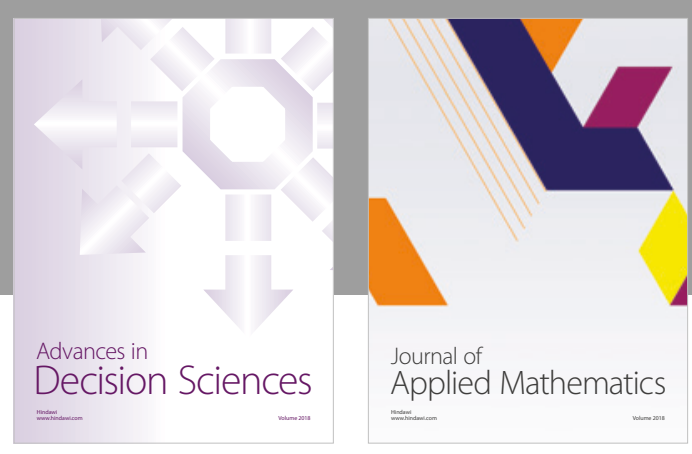

Journal of

Applied Mathematics
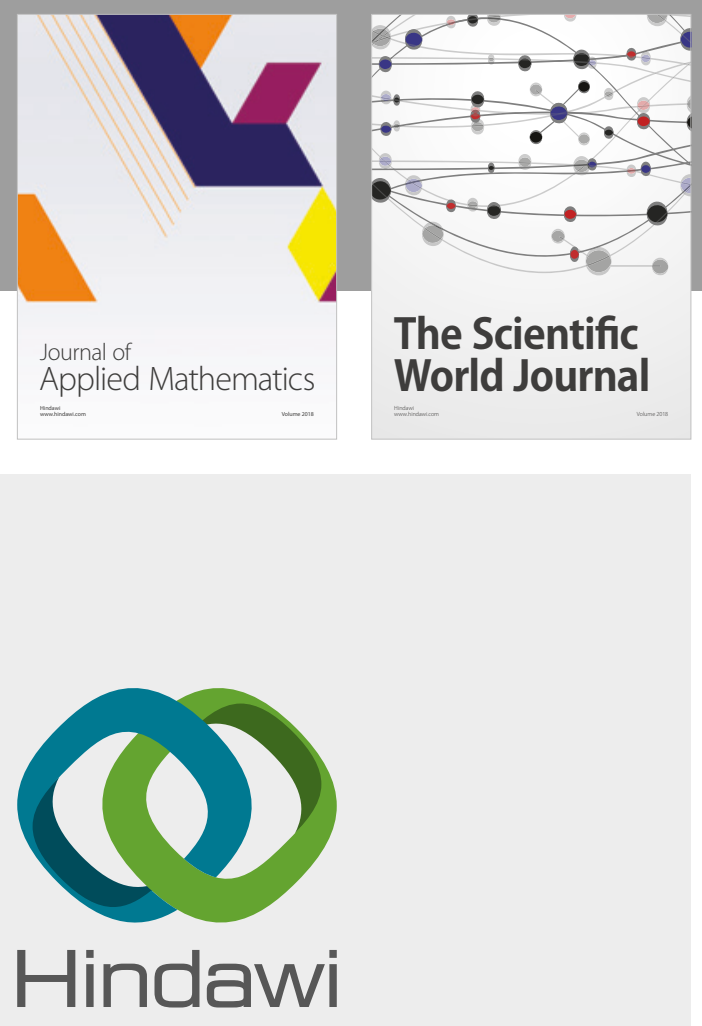

Submit your manuscripts at

www.hindawi.com

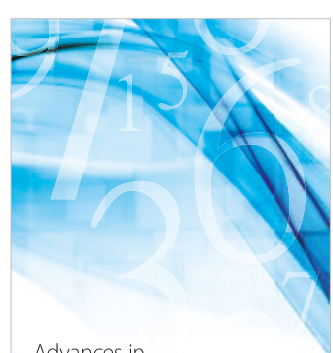

Advances in
Numerical Analysis
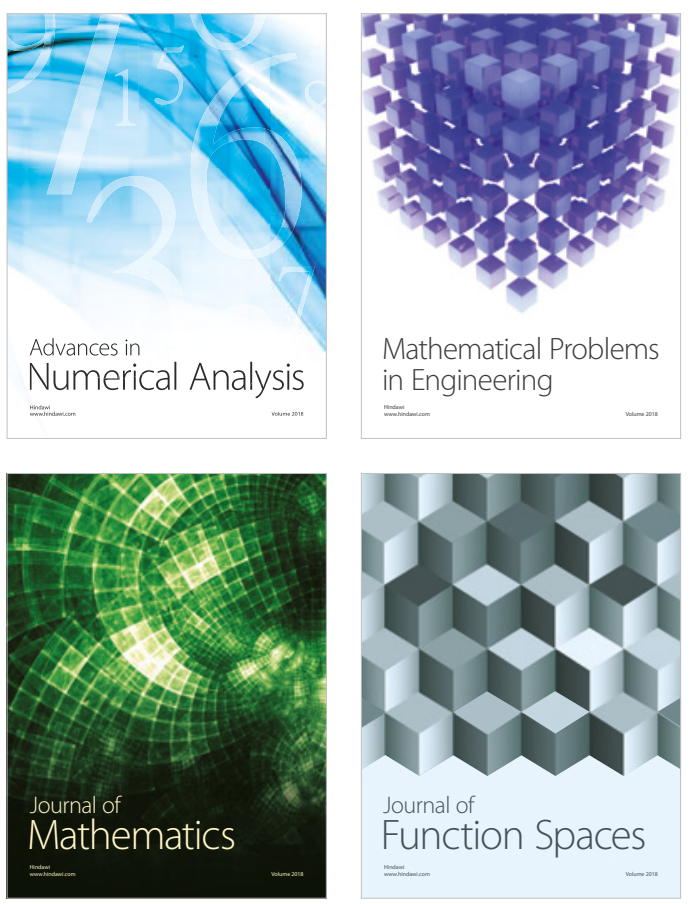

Mathematical Problems in Engineering

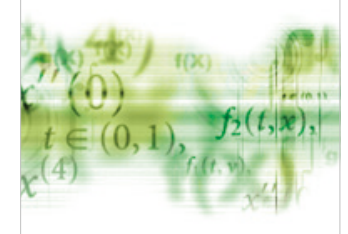

International Journal of

Differential Equations

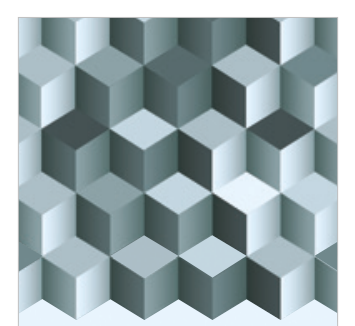

Journal of

Function Spaces

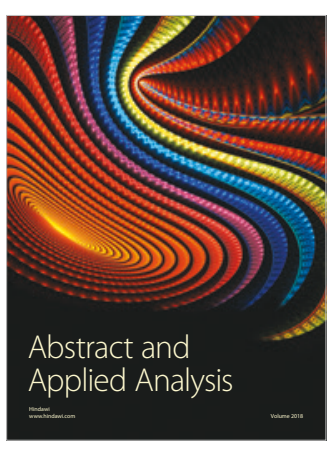

The Scientific

World Journal

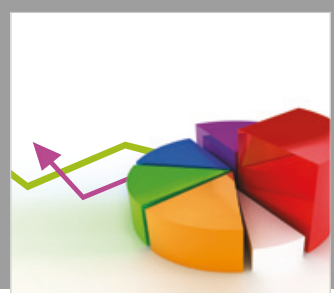

Journal of

Probability and Statistics
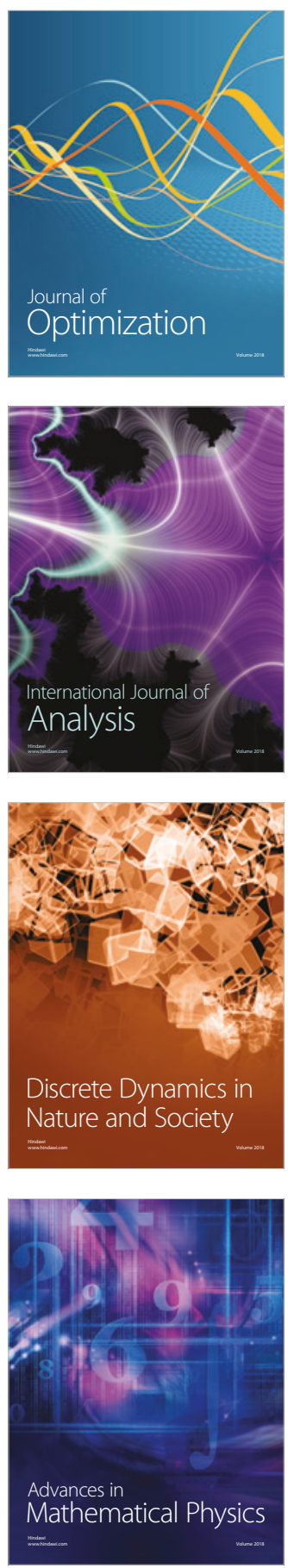